\title{
La reforma de las Administraciones Públicas y el Estado Social en la crisis económica (2012-2015) ${ }^{1}$
}

\section{The reform of the Spanish public administration and the Wellfare State during the economic crisis (2012-2015)}

\author{
Carlos Vidal Prado \\ Universidad Nacional de Educación a Distancia (UNED) \\ cvidal@der.uned.es
}

David Delgado Ramos

Universidad Nacional de Educación a Distancia (UNED) d.delgadoramos@gmail.com

\section{RESUMEN}

El trabajo analiza algunas de las reformas estructurales de las Administraciones Públicas puestas en marcha a partir de 2012 en España, como consecuencia de la crisis económica, y las políticas públicas implementadas para lograrlas, y si verdaderamente han cumplido los objetivos pretendidos (mejorar la calidad y la eficiencia de los servicios, transparencia de las Administraciones Públicas y creación de un Open Government o Gobierno Abierto). El trabajo parte de un breve un diagnóstico de las causas y consecuencias de la crisis económica, para abordar después las reformas en las Administraciones Públicas y en el modelo de Estado Social, especialmente en lo que se refiere al Empleo Público, la Educación, la Sanidad y la atención a la Dependencia. Finalmente, se realiza una breve valoración de conjunto de las soluciones adoptadas y su incidencia real en la situación actual de la economía y la Administración española.

\section{PALABRAS CLAVE}

Reformas, Administración, sanidad, educación, dependencia.

\begin{abstract}
This work analyzes some structural reforms of public administrations implemented from 2012 in Spain, as a result of the economic crisis, and public policies implemented to achieve them, and if truly met the intended objectives (improve the quality and efficiency of services, transparency in public administrations and creating an Open Government). The work part of a brief diagnosis of the causes and consequences of the economic crisis, to tackle after reforms in public administration and in the model of Welfare State, especially in what refers to public employment, education, healthcare and the attention to the dependence. Finally, a brief assessment of the adopted solutions and its real impact on the current situation of the economy and the Spanish Administration is performed.
\end{abstract}

\section{KEYWORDS}

Reforms, administration, health, education, dependence.

1 Este trabajo ha sido elaborado en el marco del Proyecto número 142, financiado por el INAP, sobre "La reforma de las administraciones públicas en España: análisis de las medidas puestas en marcha en la legislatura 2011-2015”, cuyo Investigador Principal es Carlos Vidal Prado. 


\begin{abstract}
SUMARIO
1. INTRODUCCIÓN. 2. LA CRISIS ECONÓMICA Y EL ESTADO SOCIAL. 2.1.CAUSAS Y CONTEXTO. 2.2. LA DIMENSIÓN DEL SECTOR PÚBLICO A DEBATE. 3. LAS REFORMAS ESTRUCTURALES 2012-2015. 3.1. ADMINISTRACIONES PÚBLICAS. 3.2. EDUCACIÓN. 3.3. SANIDAD Y DEPENDENCIA. 4. CONCLUSIONES.
\end{abstract}

\title{
1. INTRODUCCIÓN
}

En otoño de 2007 asistimos a los inicios de la crisis económica que se extendería durante un largo periodo en España, tras unos años de bonanza y crecimiento expansivo. Hasta entonces, las políticas públicas ejecutadas por las distintas administraciones españolas sostenían un modelo sólido y fiable del Estado Social, caracterizado por la elevada calidad de los servicios que prestaban y una inversión al alza en políticas sociales, cuyo límite ni se planteaba ni se cuestionaba.

La virulencia de la crisis y su duración, sobre todo en el periodo entre 2007 y 2014, pusieron en cuestión la solidez de este modelo, lo que conllevó el profundo replanteamiento de su alcance y naturaleza y, consecuentemente, la puesta en marcha de una serie de reformas estructurales, es decir, reformas cuya virtualidad trascendiese la mera gestión coyuntural de la crisis económica.

Estas reformas pretendieron replantear el modelo de Administración Pública y de Estado Social con un doble objetivo: delimitarlo para adecuarlo a sus verdaderos fines y objetivos $\mathrm{y}$, en segundo lugar, garantizar su sostenibilidad y viabilidad.

Junto a la reforma del Estado del Bienestar y las políticas sociales que lo definen, surgió la necesidad de analizar la dimensión de las Administraciones Públicas, ampliamente cuestionada en la opinión pública² a causa de su volumen y coste, así como su papel en la crisis económica y en la salida de ella. Las necesarias reformas estructurales se acometieron, así, con la idea de mejorar la eficacia y la eficiencia, tomando como ejes conductores la racionalización del gasto público, la eliminación de duplicidades y gasto superfluo y el impulso de la Administración Electrónica.

Estas reformas debían complementarse con el establecimiento de nuevas políticas de gobernanza pública, centradas en la transparencia de las Administraciones Públicas y la creación de un Open Government o Gobierno Abierto, con el objetivo de mejorar la interlocución con la sociedad y los ciudadanos y reducir la opacidad de la Administración.

A lo largo de este trabajo pretendemos analizar algunas reformas estructurales y las políticas públicas implementadas para lograrlas, y si verdaderamente han cumplido los objetivos pretendidos. Comenzaremos con un breve un diagnóstico de las causas y consecuencias de la crisis económica, abordaremos después algunas reformas en las Administraciones Públicas y en el modelo de Estado Social, y concluiremos con una valoración de conjunto de las soluciones adoptadas y su incidencia real en la situación actual de la economía y la Administración española.

En ese sentido, para este análisis nos centraremos fundamentalmente en el trienio 2012-2015², dado que fue el periodo donde la crisis alcanzó su mayor incidencia, y en el que se abordaron un mayor número de medidas y reformas. No obstante, entre fínales de 2014 y el inicio de 2015, comenzó a evidenciarse un nuevo escenario de progresiva reducción del desempleo y de inicio del crecimiento económico, en parte fruto de los resultados de las reformas estructurales puestas en marcha.

\footnotetext{
2 El cuestionamiento de la dimensión de las Administraciones Públicas se manifestó desde múltiples vertientes, antes y después de la crisis, siendo especialmente significativo en el caso de la prensa generalista. España, en el podio de Europa en número de funcionarios, diario Expansión, 1 de noviembre de 2010, http://www.expansion.com/2010/10/30/funcion-publica/1288389931.html; La CEOE pide que se pueda despedir a los funcionarios, diario El País, 15 de diciembre de 2011, http://elpais.com/diario/2011/12/15/economia/1323903608_850215.html; El número de funcionarios aumentó un 9,3\% entre 2007 y 2011 en toda España, diario El País, 10 de julio de 2012, http://economia.elpais.com/economia/2012/07/10/actualidad/1341918898 660207.html; El salario de los empleados públicos fue en 2010 un 30\% mayor que la media, diario El País, 24 de octubre de 2012, http://economia.elpais.com/economia/2012/10/24/actualidad/1351072633 131269.html; Las administraciones tienen hoy más funcionarios que al inicio de la crisis, diario El Mundo, 15 de junio de 2016, http://www.elmundo.es/economia/2016/06/15/576185ff46163f932d8b45ab.html; ¿Hay demasiados funcionarios y empleados públicos en España? diario El Mundo, 30 noviembre 2016, http://www.elmundo.es/economia/2016/10/30/58136a5dca47410d488b457a.html.

${ }^{3}$ Además, y desde un punto de vista metodológico, en el análisis de determinados datos, como los relativos a la evolución del número de empleados públicos, cualquier comparativa previa a enero de 2012 resulta distorsionada por la ausencia de datos completos y fiables en algunos subsectores de las Administraciones Públicas. Otros datos, relativos a la racionalización del sector público empresarial, toman como referente el año 2010 , debido a que fue en ese año cuando se iniciaron a todos los niveles los procesos de reestructuración y, por lo tanto, se cuenta con datos homogéneos.
} 


\section{LA CRISIS ECONÓMICA Y EL ESTADO SOCIAL}

\subsection{Causas y contexto}

Como ha puesto de manifiesto algún autor ${ }^{4}$, las causas de la profunda recesión económica española vivida entre finales de 2007 y finales del año 2014 son tanto de índole exógeno como endógeno.

Exógenas, porque la estrecha imbricación y conexión de las economías mundiales produjo un efecto dominó que de modo expansivo afectó a la inmensa mayoría de los países, que pasaron de un crecimiento económico sostenido, en algunos casos elevado, a la recesión ${ }^{5}$.

Endógenas, porque la rápida expansión y crecimiento que experimentó la economía española a partir del año 2001 estaba cimentada en una conjunción de factores que, a la postre, se revelaron endebles y sólo sostenibles siempre y cuando el modelo mantuviese su expansión, el empleo sostenido y el consumo creciente.

La conjunción de ambas causas, las endógenas y las exógenas, produjo una implosión del modelo económico hasta entonces vigente, con un fuerte cuestionamiento de las estructuras y del modelo del Estado del Bienestar diseñado en la segunda posguerra mundial.

Desde una perspectiva internacional, y pese a que, desde el primer momento, se adoptaron desde los bancos centrales diversas medidas con el objetivo de mitigar los efectos de la crisis económica ${ }^{6}$, la gravedad de la recesión superó cualquier posible medida de contención.

No obstante, la política monetaria, -junto con la política fiscal-, acabaría por convertirse, entre el año 2008 y 2014, en el principal instrumento de lucha contra la recesión mundial.

El resultado de ello fue un vertiginoso crecimiento del desempleo ${ }^{7}$, el freno del consumo y la inversión y el rápido crecimiento del déficit. Este último se convirtió en la principal preocupación de los países de la Unión Europea y, en particular, de los miembros de la Zona Euro y el Sistema Monetario Europeo.

En el caso particular de España, -al igual que en el resto del grupo de países englobados bajo el acrónimo PIGS-, el déficit sufrió una evolución particularmente dramática, con fortísimas oscilaciones, de tal suerte que la economía española pasó de un superávit presupuestario del $2 \%$ del PIB en 2007 a un déficit del $4,42 \%$ en 2008 , más de seis puntos de diferencia en tan sólo un año. Un déficit que volvería a incrementarse otros seis puntos en 2009, hasta alcanzar casi el $11 \%$ del PIB. Es decir, una desviación del déficit de casi trece puntos, -prácticamente, 130.000 millones de euros-, en apenas dos años. Todo ello, sin embargo, en un contexto de reducida deuda pública.

\begin{tabular}{|c|c|c|c|c|c|c|c|c|c|c|c|}
\hline \multicolumn{12}{|c|}{ EVOLUCIÓN DEL DÉFICIT EN ESPAÑA 2005-2016 } \\
\hline Porcentaje del PIB & 2006 & 2007 & 2008 & 2009 & 2010 & 2011 & 2012 & 2013 & 2014 & 2015 & 2016T2 \\
\hline Administraciones Públicas & 2,20 & 2,00 & $-4,42$ & $-10,96$ & $-9,39$ & $-9,61$ & $-10,47$ & $-7,01$ & $-6,00$ & $-5,13$ & \multirow[b]{2}{*}{$-3,07$} \\
\hline $\begin{array}{l}\text { Administraciones Públicas (sin } \\
\text { asistencia al sector financiero) }\end{array}$ & 2,20 & 2,00 & $-4,42$ & $-11,02$ & $-9,46$ & $-9,29$ & $-6,79$ & $-6,69$ & $-5,87$ & $-5,08$ & \\
\hline Administración Central & 0,89 & 1,28 & $-2,89$ & $-9,12$ & $-4,79$ & $-3,60$ & $-7,94$ & $-4,86$ & $-3,70$ & $-2,64$ & \multirow[b]{2}{*}{$-1,89$} \\
\hline $\begin{array}{l}\text { Administración Central (sin } \\
\text { asistencia al sector financiero) }\end{array}$ & 0,89 & 1,28 & $-2,89$ & $-9,19$ & $-4,86$ & $-3,27$ & $-4,26$ & $-4,54$ & $-3,57$ & $-2,59$ & \\
\hline Comunidades Autónomas & $-0,06$ & $-0,24$ & $-1,71$ & $-2,01$ & $-3,72$ & $-5,12$ & $-1,87$ & $-1,58$ & $-1,79$ & $-1,74$ & $-0,68$ \\
\hline Entidades Locales & 0,08 & $-0,31$ & $-0,48$ & $-0,55$ & $-0,65$ & $-0,79$ & 0,32 & 0,55 & 0,53 & 0,47 & 0,10 \\
\hline Seguridad Social & 1,29 & 1,27 & 0,66 & 0,72 & $-0,23$ & $-0,10$ & $-0,98$ & $-1,13$ & $-1,04$ & $-1,22$ & $-0,59$ \\
\hline
\end{tabular}

Fuente: Intervención General de la Administración del Estado ${ }^{8}$.

4 VARA CRESPO, Óscar. "Causas de la crisis financiera en el caso español". Cuadernos de economía: Spanish Journal of Economics and Finance. Vol. 32, núm. 88, 2009, págs. 141-158.

5 Como es conocido, la crisis se desató en los Estados Unidos, siendo su impacto prácticamente inmediato en la Unión Europea, debido a la globalización y la mundialización económica. Por ello, y como expone Bellod acerca de su impacto directo en el crecimiento, «La crisis económica iniciada con la implosión de la burbuja inmobiliaria en Estados Unidos ("hipotecas subprime") y la consiguiente quiebra de Lehman Brothers (2008) ha tenido un fuerte impacto en los países de la Eurozona, los cuales han pasado de una tasa media del crecimiento del PIB del 2,3\% en el periodo previo a la crisis (1999-2007) a una tasa de -0,3\% en el periodo (2008-2013)». BELLOD REDONDO, José Francisco. "PIGS: austeridad fiscal, reformas estructurales y crecimiento potencial". Revista de Economía Mundial, núm. 43, 2016 , pág. 163.

6 BORRALLO EGEA, Alberto y HIERRO RECIO, Luis Ángel. "La eficacia de la política monetaria durante la crisis económica mundial". Revista de Economía Mundial, núm. 41, 2015, pág. 45.

7 PÉREZ GONZÁlEZ, María del Carmen, SUÁREZ LLORENS, Alfonso y BLANCO CANTO, Miguel. "Un análisis regional de las políticas activas de empleo en los distintos países de la Zona Euro. Su evolución ante la crisis económica". Revista de Economía Mundial, núm. 40, 2015, pág. 147.

8 En relación con la evolución del déficit público conviene tener en cuenta el cambio en la metodología contable operado en 2014 , que cambió el modelo SEC-95 por el SEC-2010, lo que se tradujo en una modificación de los datos de déficit precedentes. 
A ello se sumó un exponencial incremento del desempleo ${ }^{9}$, -nada común al resto de países europeos-, fruto, entre otros factores, del modelo económico hasta entonces existente, que primaba la construcción ${ }^{10}$ y el mercado inmobiliario ${ }^{11}$.

Sectores con muy altos niveles de especulación en sus productos, principalmente el suelo y la vivienda, de rápido crecimiento económico y creación de empleo pero, también, con un fuerte componente coyuntural que, en un contexto de crisis, les hace destruir empleo rápidamente ${ }^{12}$.

\begin{tabular}{|c|c|c|c|c|c|c|c|c|c|c|c|}
\hline \multicolumn{12}{|c|}{ EVOLUCIÓN DEL PARO EN ESPAÑA 2006-2016 } \\
\hline AÑo & 2006 & 2007 & 2008 & 2009 & 2010 & 2011 & 2012 & 2013 & 2014 & 2015 & 2016 T3 \\
\hline No PARADOS & 1.840 .900 & 1.846 .100 & 2.595 .900 & 4.153 .500 & 4.640 .100 & 5.012 .700 & 5.811 .000 & 6.051 .100 & 5.610 .400 & 5.056 .000 & 4.320 .800 \\
\hline $\begin{array}{l}\text { TASA DE } \\
\text { PARO }\end{array}$ & 8,45 & 8,23 & 11,25 & 17,86 & 19,86 & 21,39 & 24,79 & 26,09 & 24,44 & 22,06 & 18,91 \\
\hline
\end{tabular}

Fuente: Instituto Nacional de Estadística.

En definitiva, la grave recesión económica por la que atravesaba España, caracterizada por un déficit y desempleo crecientes, unida a un retroceso de la inversión y el consumo, exigió la adopción de una serie de medidas de contención y ajuste presupuestario, centradas en la racionalización de las estructuras de gasto y en el sostenimiento de las políticas sociales.

Medidas puestas en marcha bajo el impulso del Gobierno, pero en cuya adopción influyó notablemente la presión de las institucionales internacionales ${ }^{13}$, -especialmente la Unión Europea y el Fondo Monetario Internacional-, sobre todo en el alcance de algunas de ellas, como la reforma laboral.

\subsection{La dimensión del Sector Público a debate}

Uno de los debates más recurrentes en la opinión pública ${ }^{14}$, que fue creciendo conforme la crisis y la recesión económica avanzaban, fue la dimensión del Sector Público, del conjunto de las Administraciones Públicas.

\footnotetext{
${ }^{9}$ En relación con la evolución del desempleo en España, nuestro país ha sufrido siempre grandes oscilaciones en los contextos de recesión económica. Así lo pone de relieve el Consejo Económico y Social, "La política de empleo como prioridad para salir de la crisis". Cauces: Cuadernos del Consejo Económico y Social, núm. 30, 2015, págs. 27-43.

10 Apunta García Montalvo un dato relevante: "El sector de la construcción se ha contraído en torno a un 36,5 por 100 a nivel del conjunto de España entre 2008 y 2012". GARCÍA MONTALVO, José. "Dimensiones regionales del ajuste inmobiliario en España". Papeles de economía española, núm. 138, 2013, pág. 77.

11 RUESGA BENITO, Santos; MARTÍN NAVARRO, José Luis; PÉREZ ORTIZ, Laura y PÉREZ TRUJILLO, Manuel. "2012 un año de ajuste en el empleo: análisis de coyuntura del mercado de trabajo en el primer trimestre de 2012". Temas laborales: Revista andaluza de trabajo y bienestar social, núm. 116, 2012, págs. 178-179.

12 Como explican Ortega y Peñalosa. "El desplome de la inversión en vivienda es un factor esencial para entender la dinámica y profundidad de la crisis. La inversión en vivienda, que había tenido una expansión muy intensa en el periodo de auge, hasta sobrepasar el 12\% del PIB, ha recortado su peso en el PIB hasta menos del 7\% en 2011". ORTEGA, Eloísa y PEÑALOSA, Juan. "Claves de la crisis económica española y retos para crecer en la UEM". Banco de España, Documentos Ocasionales, núm. 1.201, 2012, pág. 19.

13 Estas presiones, fruto de la falta de eficacia de las medidas y reformas impulsadas por el Gobierno en el bienio 2008-2010, alcanzaron sus mayores cotas tras la crisis griega de mayo de 2010. En ese sentido, y como apunta Molina, "Los principales países europeos e incluso Estados Unidos o China llegaron a preocuparse seriamente por el efecto que tendría un contagio de la deriva griega sobre una economía mucho más importante como la española. Así, la noche del 9 de mayo de 2010, el Gobierno se encontró angustiado por los problemas de liquidez y hubo de negociar en el Consejo de Economía y Finanzas (ECOFIN) de la UE que, a cambio del lanzamiento de un fondo de estabilidad europeo que tranquilizase a los mercados, España iba a iniciar la senda de una consolidación fiscal muy estricta y que se emprenderían finalmente las primeras reformas estructurales que hasta ese momento habian sido aplazadas". MOLINAÁLVAREZ DE CIENFUEGOS, Ignacio. "Gobierno y desgobierno de la economía: las políticas de respuesta a la crisis", en España en crisis: balance de la segunda legislatura de Rodríguez Zapatero, COLINO CÁMARA, César y COTARELO GARCÍA, Ramón (coords.). Editorial Tirant Lo Blanch, Valencia, 2012, pág. 65.

14 En la encuesta online del diario El Mundo celebrada el 30 de enero de 2009 ¿Cree usted que el número de funcionarios españoles es excesivo?, el 85\% de los casi 20.00 encuestados respondió de modo afirmativo, http://www.elmundo.es/debate/2009/01/1673/ prevotaciones1673.html. En 2016, un editorial del mismo periódico titulado La eterna reforma pendiente de las Administraciones Públicas cuestionaba las reformas emprendidas durante la crisis, apuntando que el sector público español seguía teniendo un gran tamaño: http://www.elmundo.es/opinion/2016/04/14/570e8ba9ca4741e6658b459a.html.
} 
Un debate que también se producía en el ámbito doctrinal ${ }^{15} \mathrm{y}$ en el que, junto con el lógico cuestionamiento de las políticas públicas adoptadas en la época de bonanza y expansión económica se mezclaban, también, planteamientos de índole objetivo, centrados en el uso y gestión del dinero público y en la dimensión necesaria del conjunto de las Administraciones Públicas para realizar las políticas encomendadas ${ }^{16}$.

Como se muestra en el cuadro adjunto, entre el año 2004, cuando la economía española crecía a un ritmo elevado, con desempleo decreciente, y el año 2012, el año más difícil de la crisis económica en España, el número de empleados públicos se incrementó en un $14,14 \%, 332.757$ personas más ${ }^{17}$.

\begin{tabular}{|c|c|c|c|c|c|c|c|c|c|c|c|}
\hline \multicolumn{12}{|c|}{ EVOLUCIÓN DEL NÚMERO DE EMPLEADOS PÚBLICOS EN ESPAÑA 2004-2012 } \\
\hline ADMINISTRACIÓN & $\begin{array}{l}\text { TIPOLOGÍA DE } \\
\text { EMPLEADOS }\end{array}$ & 2004 & 2005 & 2006 & 2007 & 2008 & 2009 & 2010 & 2011 & 2012 & Var. \% 2004-2012 \\
\hline \multirow{4}{*}{$\begin{array}{l}\text { ADMINISTRACIÓN } \\
\text { PÚBLICA ESTATAL }\end{array}$} & Funcionarios & 395.622 & 398.469 & 404.064 & 412.601 & 421.250 & 433.806 & 451.343 & 456.933 & 457.596 & $15,5 \%$ \\
\hline & Personal Laboral & 136.782 & 134.934 & 133.764 & 131.000 & 130.105 & 129.075 & 126.939 & 124.595 & 113.063 & $-8,9 \%$ \\
\hline & Otro Personal & 9.408 & 7.465 & 8.888 & 9.605 & 10.196 & 12.140 & 13.277 & 11.285 & 11.202 & $20 \%$ \\
\hline & TOTAL & 541.812 & 540.868 & 546.716 & 553.206 & 561.551 & 575.021 & 591.559 & 592.813 & 581.861 & $7,4 \%$ \\
\hline \multirow{4}{*}{$\begin{array}{l}\text { COMUNIDADES } \\
\text { AUTÓNOMAS }\end{array}$} & Funcionarios & 721.848 & 726.262 & 767.689 & 805.825 & 844.382 & 876.691 & 888.403 & 900.298 & 920.681 & $24,7 \%$ \\
\hline & Personal Laboral & 135.589 & 125.204 & 145.350 & 148.107 & 150.794 & 148.222 & 150.997 & 149.287 & 143.869 & $10,1 \%$ \\
\hline & Otro Personal & 302.514 & 339.141 & 310.090 & 306.643 & 305.056 & 307.931 & 309.092 & 292.700 & 287.333 & $-3,2 \%$ \\
\hline & TOTAL & 1.159 .951 & 1.190 .607 & 1.223.129 & 1.260 .575 & 1.300 .232 & 1.332 .844 & 1.348 .492 & 1.342 .285 & 1.351 .883 & $16,55 \%$ \\
\hline \multirow{4}{*}{$\begin{array}{l}\text { ENTIDADES } \\
\text { LOCALES }\end{array}$} & Funcionarios & 120.752 & & 199.441 & 205.230 & 212.705 & 213.985 & 215.621 & 217.785 & 220.573 & $80,4 \%$ \\
\hline & Personal Laboral & 438.033 & & 339.049 & 359.537 & 371.453 & 371.331 & 397.958 & 386.152 & 336.430 & $-11,8 \%$ \\
\hline & Otro Personal & & & 33.829 & 37.234 & 39.056 & 44.189 & 44.326 & 43.551 & 40.209 & $18,9 \%$ \\
\hline & TOTAL & 558.785 & 563.392 & 572.319 & 602.001 & 623.214 & 629.505 & 657.905 & 647.488 & 597.212 & $6,88 \%$ \\
\hline \multirow{4}{*}{ UNIVERSIDADES } & Funcionarios & 60.961 & 62.603 & 62.632 & 62.374 & 62.436 & 62.529 & 63.107 & 63.159 & 74.179 & $21,68 \%$ \\
\hline & Personal Laboral & 10.652 & 27.027 & 28.475 & 30.546 & 31.597 & 33.014 & 33.597 & 33.747 & 69.839 & $555,64 \%$ \\
\hline & Otro Personal & 20.919 & 2.917 & 2.901 & 3.336 & 3.816 & 3.987 & 3.968 & 3.878 & 10.863 & $-48,07 \%$ \\
\hline & TOTAL & 92.532 & 92.547 & 94.008 & 96.256 & 97.849 & 99.530 & 100.672 & 100.784 & 154.881 & $67,38 \%$ \\
\hline \multirow{4}{*}{$\begin{array}{c}\text { TOTAL } \\
\text { ADMINISTRACIONES } \\
\text { PÚBLICAS }\end{array}$} & Funcionarios & 1.299 .183 & & 1.433 .826 & 1.486 .030 & 1.540 .773 & 1.587 .011 & 1.618 .474 & 1.638 .175 & 1.673 .029 & $28,78 \%$ \\
\hline & Personal Laboral & 721.056 & & 646.638 & 669.190 & 683.949 & 681.642 & 709.491 & 693.781 & 663.201 & $-8,02 \%$ \\
\hline & Otro Personal & 332.841 & & 355.708 & 356.818 & 358.124 & 368.247 & 370.663 & 351.414 & 349.607 & $5,04 \%$ \\
\hline & TOTAL & 2.353 .080 & 2.387.414 & 2.436 .172 & 2.512 .038 & 2.582 .846 & 2.636 .900 & 2.698 .628 & 2.683.370 & 2.685 .837 & $14,14 \%$ \\
\hline
\end{tabular}

Fuente: Boletín Estadístico del Personal al Servicio de las Administraciones Públicas, Ministerio de Hacienda y Administraciones Públicas.

\begin{tabular}{|l|c|c|c|c|c|c|c|c|c|c|c|c|}
\hline \multicolumn{1}{|c|}{ EVOLUCIÓN DEL NÚMERO DE EMPLEADOS PÚBLICOS DE LAS COMUNIDADES AUTÓNOMAS 2004-2012 } \\
\hline \multicolumn{1}{|c|}{ ÁREAS } & Enero 04 & Enero 05 & Enero 06 & Enero 07 & Enero 08 & Enero 09 & Enero $\mathbf{1 0}$ & Enero $\mathbf{1 1}$ & Enero $\mathbf{1 2}$ & Variación & \% $\mathbf{2 0 0 4 / 2 0 1 2}$ \\
\hline ADMINISTRACIÓN DE JUSTICIA & 29.351 & 29.974 & 31.481 & 31.974 & 32.710 & 37.309 & 37.789 & 38.348 & 39.373 & $\mathbf{1 0 . 0 2 2}$ & $\mathbf{3 4 , 1 5 \%}$ \\
\hline CONSEJERIAS YIO DEPARTAMENTOS Y OO.AA. & 242.243 & 225.904 & 234.091 & 236.826 & 242.776 & 243.081 & 241.518 & 238.401 & 225.671 & $\mathbf{- 1 6 . 5 7 2}$ & $\mathbf{- 6 , 8 4 \%}$ \\
\hline DOCENCIA NO UNIVERSITARIA & 442.421 & 456.827 & 465.901 & 477.706 & 489.468 & 504.192 & 511.020 & 507.772 & 515.785 & $\mathbf{7 3 . 3 6 4}$ & $\mathbf{1 6 , 5 8 \%}$ \\
\hline INSTITUCIONES SANITARIAS & 380.587 & 408.405 & 419.249 & 435.451 & 456.536 & 466.021 & 470.707 & 472.222 & 484.915 & $\mathbf{1 0 4 . 3 2 8}$ & $\mathbf{2 7 , 4 1 \%}$ \\
\hline INSTITUCIONES PENITENCIARIAS & 2.852 & 2.886 & 3.234 & 3.356 & 4.056 & 4.480 & 4.803 & 4.811 & 4.776 & $\mathbf{1 . 9 2 4}$ & $\mathbf{6 7 , 4 6 \%}$ \\
\hline POLICIA & 10.137 & 11.407 & 12.686 & 14.053 & 15.280 & 16.204 & 17.159 & 18.032 & 18.529 & $\mathbf{8 . 3 9 2}$ & $\mathbf{8 2 , 7 9 \%}$ \\
\hline TOTAL & $\mathbf{1 . 1 0 7 . 5 9 1}$ & $\mathbf{1 . 1 3 5 . 4 0 3}$ & $\mathbf{1 . 1 6 6 . 6 4 2}$ & $\mathbf{1 . 1 9 9 . 3 6 6}$ & $\mathbf{1 . 2 4 0 . 8 2 6}$ & $\mathbf{1 . 2 7 1 . 2 8 7}$ & $\mathbf{1 . 2 8 2 . 9 9 6}$ & $\mathbf{1 . 2 7 9 . 5 8 6}$ & $\mathbf{1 . 2 8 9 . 0 4 9}$ & $\mathbf{1 8 1 . 4 5 8}$ & $\mathbf{1 6 , 3 8 \%}$ \\
\hline
\end{tabular}

Fuente: Boletín Estadístico del Personal al Servicio de las Administraciones Públicas, Ministerio de Hacienda y Administraciones Públicas.

En el cuadro superior se observa, en ese sentido, la evolución pormenorizada del conjunto de los empleados públicos en las Comunidades Autónomas, cuyo presupuesto conjunto se destina, en más de un $80 \%$, al llamado gasto social y políticas asociadas.

Así, entre enero de 2004 y enero de $2012^{18}$, el número de empleados públicos de las Comunidades Autónomas se incrementó en 181.458 personas, un 16,38\% más. Resulta detacable que mientras que la

15 SÁNCHEZ MORÓN, Miguel. "El empleo público en España: problemas actuales y retos de futuro". Revista Aragonesa de Administración Pública, núm. 13 (monográfico dedicado a El empleo público en Aragón y tendencias de futuro), 2011, págs. 25-26.

${ }_{16}$ Conviene tener en cuenta, como apuntan Pollit y Bouckaert, que la reforma de la gestión pública "se trata de un medio para la consecución de una multiplicidad de fines". POLLIT, Christopher y BOUCKAERT, Geert. La reforma de la gestión pública: un análisis comparado. Instituto Nacional de Administración Pública, Madrid, 2010, pág. 23.

17 Desglosado por Administraciones Públicas: la Administración General del Estado incrementó su personal en 40.049 personas, un 7,4\%., las Comunidades Autónomas lo hicieron en 191.932 personas, un 15,7\%, las Entidades Locales en 38.427 personas, un $6,88 \%$ y las Universidades incrementaron su personal en 62.349 personas, un $67,38 \%$ más. Conviene hacer constar, no obstante, que hasta enero de 2012 el Boletín Estadístico del Personal al Servicio de las Administraciones Públicas únicamente publicaba datos del personal de Universidades inscrito en el Registro Central de Personal. A partir de esa fecha se incorporan datos de todos los efectivos de las Universidades, inscritos y no inscritos en el Registro Central de Personal. Esta modificación metodológica que supone la incorporación de todo el personal significa un incremento de 54.097 efectivos en enero de 2012. Conviene señalar, por último, que de las Universidades, hasta el año 2012, no se disponía de información completa y fiable de su personal.

18 Siendo el año 2002 el año de culminación del traspaso de competencias a las Comunidades Autónomas, con la trasferencia de la Sanidad, y 2003 un año de transición en el ejercicio de la competencia en esta materia, el año 2004 es el primer año en el que la 
estructura burocrática de las consejerías, departamentos y organismos autónomos descendía en casi un $7 \%$, se incrementó notablemente el personal de sanidad, -un 27,41\% más-, y educación, -un 16,58\% más-. Incremento que resulta especialmente significativo en algunas Comunidades Autónomas en los primeros estadios de la crisis, entre 2007 y 2011.

Sin embargo, estos aumentos contrastaban con el moderado crecimiento de la población en el mismo periodo ${ }^{19} \mathrm{y}$, también, con el mantenimiento del número de ocupados en el sector privado ${ }^{20}$. Con todo, lo más significativo radicaba en el hecho de que, desatada la crisis económica, el número de empleados públicos se siguiese incrementando entre 2008 y $2012^{21}$.

Una parte de la opinión pública consideraba excesiva, incluso "elefantiásica» ${ }^{22}$ la dimensión del Sector Público en sus diversos subsectores, máxime cuando los medios de comunicación airearon no sólo un buen número de casos de corrupción sino que, en relación con ellos, comenzaron a asociar a las Administraciones Públicas durante la época de bonanza económica con el descontrol en la gestión de los recursos, el despilfarro y la corrupción ${ }^{23}$.

Por ello, como ya hemos dicho, una parte de la sociedad ${ }^{24} \mathrm{y}$ un sector de los medios de comunicación, cuestionaban el supuesto tamaño excesivo de las Administraciones Públicas. Al relacionarlo con la recesión y la crisis económica, exigían ajustes similares los que se estaban produciendo en el sector privado.

\section{LAS REFORMAS ESTRUCTURALES 2012-2015}

\subsection{Administraciones Públicas}

Dado el fuerte cuestionamiento de que fue objeto, una de las reformas estructurales de mayor calado que se debía acometer era la de las Administraciones Públicas, en un doble sentido: el de la racionalización de estructuras y supresión de duplicidades y el de la reducción en el número de empleados públicos. Ello sin olvidar las relativas a la reducción de cargas administrativas y el impulso de la Administración Electrónica, concebida esta última como un instrumento para modernizar la eficacia y la eficiencia de la acción administrativa.

Con este planteamiento se creó, en octubre de 2012, la Comisión para la Reforma de las Administraciones Públicas ${ }^{25}$ (CORA). En su seno se integraron cuatro subcomisiones ${ }^{26}$, con el objetivo de "realizar un estudio integral de las Administraciones Públicas para identificar las áreas de mejora y las medidas a adoptar para hacerlas más ágiles, eficientes y cercanas a los ciudadanos».

competencia sanitaria es ejercida en toda su dimensión por las Comunidades Autónomas.

19 Entre enero de 2004 y enero de 2012 la población española se incrementó en 4.270 .762 personas, un 10,04\% más.

20 También en ese mismo periodo, el número de ocupados descendió ligeramente, pasando de 17.770.200 a 17.765.100, 5.100 personas menos, un $0,03 \%$

21 Concretamente, 102.991 personas más, un 3,99\%.

22 Así la definía en 2010 el expresidente de la Comisión Nacional del Mercado de Valores, Manuel Conthe: "Manuel Conthe denuncia la elefantiasis de la administración", diario $A B C, 18$ de noviembre de 2010. http://www.abc.es/20101118/economia/manuelconthe-denuncia-elefantiasis-20101118.html.

23 "Hacia una Auditoría General del Estado", diario Cinco Días, 9 de octubre de 2014, http://cincodias.com/cincodias/2014/10/09/ economia/1412880707 551783.html.

"Un mercado más unido y menos burocracia", diario Expansión, 14 de junio de 2016, http://www.expansion.com/economia/politica/ elecciones-generales/2016/06/14/575fc956268e3e024b8b4611.html.

"Percepciones y cifras de la corrupción en España”, Infolibre.es, 7 de febrero de 2016. Extracto del libro de Carles Ramió La renovación de la función pública, http://www.infolibre.es/noticias/politica/2016/02/07/libro_44424_1012.html.

${ }^{24}$ La patronal, por ejemplo, llegó a sostener que no sólo había muchos, sino que, incluso "A lo mejor es mejor ponerles un subsidio a que estén en la Administración consumiendo papel, consumiendo teléfono y tratando de crear leyes. Eso tiene un coste tremendo». "La patronal descalifica al INE y niega que haya casi seis millones de parados", diario El País, 8 de febrero de 2013 , http:// economia.elpais.com/economia/2013/02/07/actualidad/1360270022_879827.html.

Poco antes, en 2011, la CEOE había abogado por el despido de funcionarios. "La CEOE reclama que se pueda despedir a los funcionarios", diario El País, 15 de diciembre de 2011, http://elpais.com/diario/2011/12/15/economia/1323903608_850215.html.

25 La Comisión, creada mediante Acuerdo del Consejo de Ministros del 26 de octubre de 2012, presentó su informe en el Consejo de Ministros de 21 de junio de 2013, con 217 propuestas y 222 medidas de las que 140 afectaban al Estado y a las Comunidades Autónomas y 82 exclusivamente a la Administración General del Estado. En el último Informe Ejecutivo de balance de la CORA se recoge un grado de ejecución del $87 \%$ y unos ahorros totales cuantificados de 30.947.624.397 euros para el conjunto de las Administraciones Públicas y 4.026.554.224 euros para ciudadanos y empresas.

26 Duplicidades administrativas, simplificación administrativa, gestión de servicios y medios comunes y Administración Institucional. 
Como se observa en los cuadros adjuntos, la racionalización del Sector Público operó en múltiples sectores, siendo los más significativos, por volumen y coste, los relativos al número de empleados públicos y entes.

La norma directamente relacionada con la racionalización de las Administraciones Públicas fue el Real Decreto-ley 20/2012, de 13 de julio, de medidas para garantizar la estabilidad presupuestaria y de fomento de la competitividad ${ }^{27}$. Su Preámbulo constata la necesidad urgente de "continuar adoptando una serie de medidas extraordinarias» dirigidas a racionalizar y reducir el gasto de personal de las Administraciones públicas y a incrementar la eficiencia de su gestión, necesidad que viene exigida por el proceso de consolidación fiscal y la sostenibilidad de las cuentas públicas.

En este trabajo analizaremos solamente las medidas que suponen reformas estructurales de la Administración, bien por la reducción de empleados públicos, bien por la reducción de entes o estructuras administrativas. No abordaremos otras iniciativas económicas o laborales, como el aplazamiento de la paga extraordinaria de diciembre de 2012 o la reducción de días de libre disposición para todo el personal del sector público.

En ese sentido, y en relación al número de empleados públicos, la racionalización efectuada se centró en la no reposición de vacantes vía reducción de la tasa de reposición de efectivos, que se ha ido concretando en la Ley de Presupuestos Generales del Estado año a año, y que se ha convertido en el instrumento más eficiente de reducción de estructuras sin coste social, ya que, al operar vía no reposición de jubilaciones, no ha incrementado el desempleo.

La propia evolución de la tasa de reposición de efectivos así lo demuestra, ya que 2008 fue el último año en el que se estableció en la Ley de Presupuestos Generales del Estado una tasa del 100\%. Desde 2009 se establece, con carácter general, una tasa de hasta el $30 \%$, que para 2010 se reduce a un máximo del 15\%, pero en el ámbito de la Administración General del Estado, y como consecuencia del Acuerdo de Consejo de Ministros de 21 de enero de 2010, es del 10\%. Para 2011 se establece una tasa de reposición con un máximo del 10\%, ampliable al $30 \%$ para las Entidades Locales menores de 20.000 habitantes y funcionarios docentes no universitarios. Para 2012, 2013 y 2014 se congela la tasa general, al 0\%, estableciéndose una excepción en determinados sectores y Administraciones en los que se autoriza una tasa de reposición de hasta el 10\%. En 2015 se mantuvo esa congelación, incrementándose hasta el 50\% la tasa de reposición permitida a ciertos sectores y administraciones prioritarios. Por último, para 2016, se establece una tasa de reposición del $50 \%$, con carácter general, que excepcionalmente se aumenta hasta el $100 \%$ a ciertos sectores y administraciones prioritarios, como la Acción Exterior del Estado y la Asistencia directa a los usuarios de los servicios sociales y gestión de prestaciones y políticas activas en materia de empleo.

Además, la reducción de la tasa de reposición también ha conllevado un incremento de la productividad de la función pública en general ${ }^{28} \mathrm{y}$, en términos de coste, una reducción de la masa salarial de los efectivos en un 4,87\%, más de 330 millones de euros, entre 2011-2015. No onbstante, la elevada edad media ${ }^{29}$ del conjunto de los empleados públicos, superior a los 52 años, ha diluido en buena medida la eficacia de la medida, pues -entre otras cosas- el envejecimiento de las plantillas es notable y, a medio plazo, pueden producirse situaciones graves de falta de personal en algunos departamentos y sectores.

${ }_{27}$ Posteriormente se completó con otras normas, fundamentalmente la Ley 15/2014, de 16 de septiembre, de racionalización del Sector Público y otras medidas de reforma administrativa.

${ }^{28}$ El incremento de la productividad ha sido el resultado, fundamentalmente, de la conjunción de dos factores: la reducción de la tasa de reposición de efectivos desde 2009 y del incremento de la jornada laboral operada mediante el Real Decreto-ley 20/2012. MONTESINOS, Antonio, y PÉREZ GARCÍA, Javier J., "Los cambios en la estructura y composición del empleo público durante la crisis", Cuadernos de Información Económica, núm. 249, noviembre-diciembre 2015. Esta cuestión ha sido también puesta de manifiesto por el Instituto Nacional de Estadística en su Encuesta Trimestral de Costes Laborales en el Sector de Administración Pública y Defensa, y Seguridad Social obligatoria (que comprende los tres niveles de las Administraciones Públicas), donde el absentismo por incapacidad temporal, es decir, el número medio de horas anuales no trabajadas por incapacidad temporal por trabajador, se redujo $5,70 \%$ en el periodo 2011-2014. En el Sector Servicios, con arreglo a esa misma fuente, el número medio de horas anuales no trabajadas por incapacidad temporal por trabajador se redujo un 10,54\% en el periodo 2011-2014. Sin embargo, a partir del año 2014, se observa un repunte del absentismo por incapacidad temporal a nivel nacional y en todos los sectores productivos según la Encuesta Trimestral de Costes Laborales del Instituto Nacional de Estadística.

${ }^{29}$ Según el último Boletín Estadístico del Personal al servicio de las Administraciones Públicas, correspondiente a julio de 2016, el $74,74 \%$ de los funcionarios de los ministerios y organismos autónomos tiene entre 40 y 59 años, siendo la edad media superior a los 52 años. 


\begin{tabular}{|l|c|c|c|c|}
\hline \multirow{2}{*}{ SUBSECTORES } & \multicolumn{4}{c|}{ PERSONAL AL SERVICIO DE LAS } \\
& \multicolumn{2}{|c|}{ ADMINISTRACIONES PÚBLICAS 2012-2016 } \\
\cline { 2 - 5 } & Enero 2012 & Enero 2016 & Variación & Var. \% \\
\hline Administración Pública Estatal & 581.861 & 527.801 & $\mathbf{- 5 4 . 0 6 0}$ & $\mathbf{- 9 , 2 9 \%}$ \\
\hline Comunidades Autónomas & 1.351 .883 & 1.294 .765 & $\mathbf{- 5 7 . 1 1 8}$ & $\mathbf{- 4 , 2 3 \%}$ \\
\hline Entidades Locales & 597.212 & 548.944 & $-\mathbf{- 4 8 . 2 6 8}$ & $\mathbf{- 8 , 0 8 \%}$ \\
\hline Universidades & 154.881 & 147.770 & $\mathbf{- 7 . 1 1 1}$ & $\mathbf{- 4 , 5 9 \%}$ \\
\hline \multicolumn{1}{|c|}{ TOTAL } & $\mathbf{2 . 6 8 5 . 8 3 7}$ & $\mathbf{2 . 5 1 9 . 2 8 0}$ & $\mathbf{- 1 6 6 . 5 5 7}$ & $\mathbf{- 6 , 2 0 \%}$ \\
\hline
\end{tabular}

Fuente: Boletín Estadístico del Personal al Servicio de las Administraciones Públicas, Ministerio de Hacienda y Administraciones Públicas.

\begin{tabular}{|c|c|c|c|c|}
\hline \multirow{2}{*}{ TIPOLOGÍAS } & \multicolumn{4}{c|}{ MASA SALARIAL FUNCIONARIOS Y LABORALES 2011/2015 } \\
\cline { 2 - 5 } & $\mathbf{2 0 1 1}$ & $\mathbf{2 0 1 5}$ & Diferencia & $\%$ \\
\hline Funcionarios AGE & $3.440 .519 .448,15$ & $3.259 .030 .075,28$ & $\mathbf{- 1 8 1 . 4 8 9 . 3 7 2 , 8 7}$ & $\mathbf{- 5 , 2 8 \%}$ \\
\hline Funcionarios otros OOPP & $956.083 .304,36$ & $979.374 .112,35$ & $\mathbf{2 3 . 2 9 0 . 8 0 7 , 9 9}$ & $\mathbf{2 , 4 4 \%}$ \\
\hline Funcionarios de la SS & $895.476 .521,71$ & $860.079 .125,23$ & $\mathbf{- 3 5 . 3 9 7 . 3 9 6 , 4 8}$ & $\mathbf{- 3 , 9 5 \%}$ \\
\hline Total funcionarios & $5.292 .079 .274,22$ & $5.098 .483 .312,86$ & $\mathbf{- 1 9 3 . 5 9 5 . 9 6 1 , 3 6}$ & $\mathbf{- 3 , 6 6 \%}$ \\
\hline Laborales AGE & $1.268 .665 .307,36$ & $1.133 .130 .773,85$ & $\mathbf{- 1 3 5 . 5 3 4 . 5 3 3 , 5 1}$ & $\mathbf{- 1 0 , 6 8 \%}$ \\
\hline Laborales OOPP & $125.930 .514,07$ & $124.708 .596,66$ & $\mathbf{- 1 . 2 2 1 . 9 1 7 , 4 1}$ & $\mathbf{- 0 , 9 7 \%}$ \\
\hline Laborales SS & $107.913 .499,63$ & $107.452 .565,04$ & $\mathbf{- 4 6 0 . 9 3 4 , 5 9}$ & $\mathbf{- 0 , 4 3 \%}$ \\
\hline Total laborales & $1.502 .509 .321,06$ & $1.365 .291 .935,55$ & $\mathbf{- 1 3 7 . 2 1 7 . 3 8 5 , 5 1}$ & $\mathbf{- 9 , 1 3 \%}$ \\
\hline TOTAL & $\mathbf{6 . 7 9 4 . 5 8 8 . 5 9 5 , 2 8}$ & $\mathbf{6 . 4 6 3 . 7 7 5 . 2 4 8 , 4 1}$ & $\mathbf{- 3 3 0 . 8 1 3 . 3 4 6 , 8 7}$ & $\mathbf{- 4 , 8 7 \%}$ \\
\hline
\end{tabular}

Fuente: Boletín Estadístico del Personal al Servicio de las Administraciones Públicas, Ministerio de Hacienda y Administraciones Públicas. Los funcionarios de la Administración General del Estado incluyen a funcionarios de carrera, interinos, personal eventual y en prácticas. No se incluyen investigadores del CSIC.

Los datos revelan que, entre 2012 y 2016, las Administraciones Públicas disminuyeron de forma muy significativa su personal. La Administración del Estado fue la que más redujo sus efectivos en ese periodo, al disminuir casi un $10 \%$ el número de sus empleados públicos.

Resalta especialmente el descenso en el área de la estructura burocrático-administrativa de los departamentos ministeriales y sus organismos autónomos, con cerca del $15 \%$ menos de efectivos. En otras palabras, un $30 \%$ del total de empleados públicos que ha reducido la Administración Pública estatal entre 2012 y 2016.

Por tanto, la mayor reducción de personal en la Administración de Estado, -como también en el resto de Administraciones Públicas, aunque en menor medida-, se concentró en la burocracia administrativa, no en otras áreas, -como las Fuerzas y Cuerpos de Seguridad del Estado, las Fuerzas Armadas y la Administración de Justicia-, donde, aun disminuyendo sus efectivos de forma importante, la contracción fue mucho menor.

Mención especial merece el significativo descenso operado en las Entidades Públicas Empresariales y los Organismos Públicos con régimen específico, de más de un 33\% entre los años 2012 y 2016 y que, en puridad, no es tal, dado que entre enero de 2014 y enero de 2015 se produjo una modificación de la estructura de Renfe-Operadora y su fraccionamiento en cuatro sociedades mercantiles estatales ${ }^{30}$, lo que supuso la salida del ámbito del Boletín Estadístico de 14.133 efectivos. Una modificación no menor que ha supuesto, en definitiva, una notable reducción del porcentaje final en estas entidades y organismos.

${ }^{30}$ Esta medida, puesta en marcha mediante el Real Decreto-ley 22/2012, de 20 de julio, por el que se adoptan medidas en materia de infraestructuras y servicios ferroviarios, tomó carta de naturaleza entre 2013 (Real Decreto-ley 4/2013, de 22 de febrero, de medidas de apoyo al emprendedor y de estímulo del crecimiento y de la creación de empleo) y 2014. 
GAPP. Nueva Época - N.1 17, mayo 2017 - ISSN: 1989-8991 - DOI: 10.24965/gapp.v0i17.10400 - [Págs. 40-62]

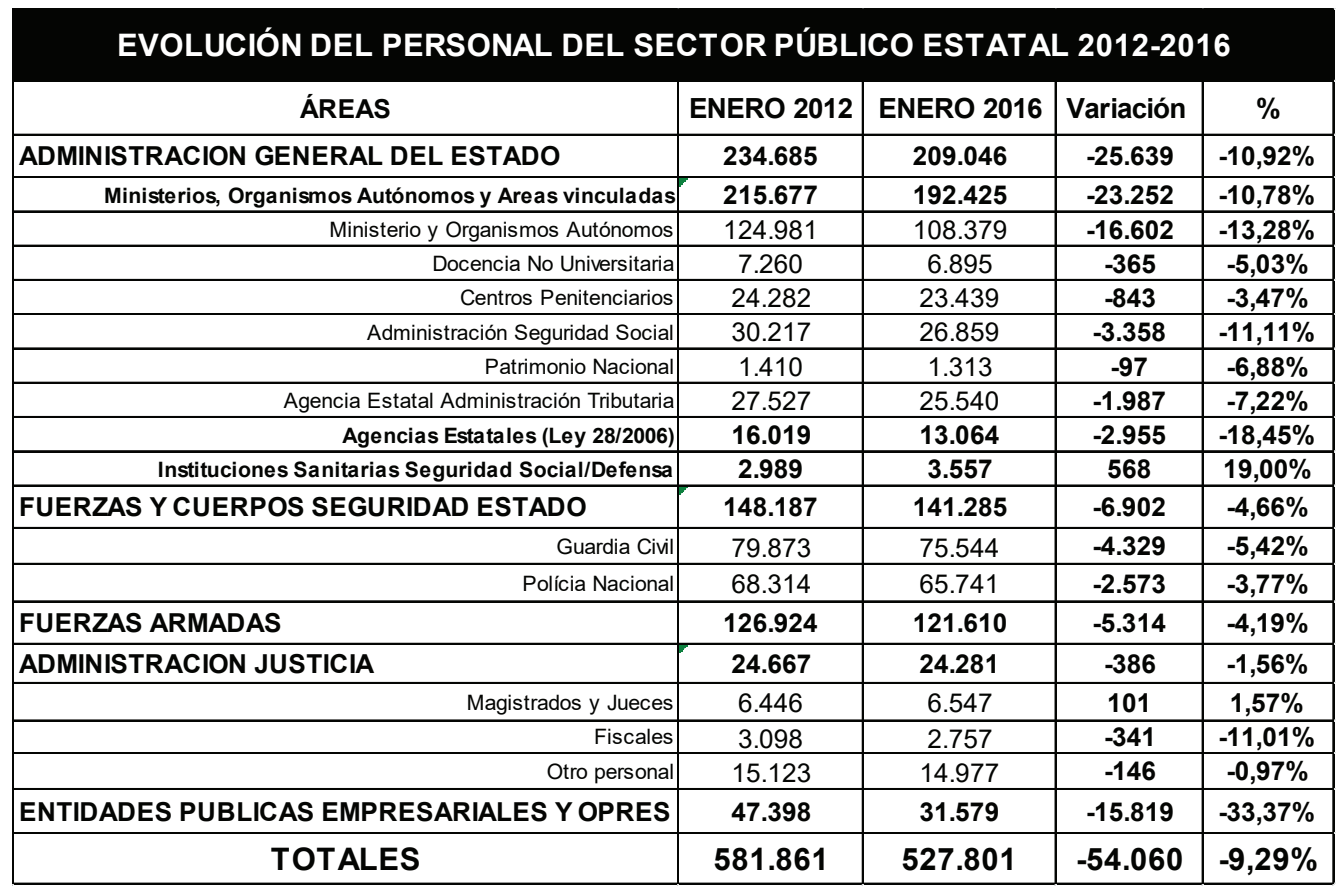

Fuente: Boletín Estadístico del Personal al Servicio de las Administraciones Públicas, Ministerio de Hacienda y Administraciones Públicas.

Las Comunidades Autónomas, por su parte, responsables de la gestión de las políticas sociales y, consecuentemente, de su personal y gasto, $-\mathrm{y}$, precisamente por ello, del $51 \%$ del volumen total de empleados públicos-, también redujeron mayoritariamente su personal en sus consejerías y departamentos, es decir, en la estructura burocrático-administrativa, con más del $8 \%$. Un descenso relevante si se compara con la reducción que se ha producido en las áreas sociales, del 4,86\% en Sanidad y de apenas un 2,01\% en Educación.

\begin{tabular}{|l|c|c|c|c|}
\hline \multirow{2}{*}{ ÁREAS DE ACTIVIDAD } & \multicolumn{3}{c|}{ EVOLUCIÓN PERSONAL COMUNIDADES AUTÓNOMAS 2012-2016 } \\
\cline { 2 - 5 } & Enero 2012 & Enero 2016 & Variación & Var. \% \\
\hline Consejerías y sus Organismos Autónomos & 230.447 & 210.961 & $-\mathbf{1 9 . 4 8 6}$ & $\mathbf{- 8 , 4 6 \%}$ \\
\hline Área de la docencia no universitaria & 550.306 & 539.224 & $-\mathbf{- 1 1 . 0 8 2}$ & $\mathbf{- 2 , 0 1 \%}$ \\
\hline Instituciones sanitarias Sistema Nacional de Salud & 505.185 & 480.626 & $\mathbf{- 2 4 . 5 5 9}$ & $-\mathbf{4 , 8 6 \%}$ \\
\hline Administración de Justicia & 39.373 & 38.078 & $\mathbf{- 1 . 2 9 5}$ & $\mathbf{- 3 , 2 9 \%}$ \\
\hline Fuerzas de Seguridad & 26.572 & 25.876 & $\mathbf{- 6 9 6}$ & $\mathbf{- 2 , 6 2 \%}$ \\
\hline \multicolumn{1}{|c|}{ TOTAL } & $\mathbf{1 . 3 5 1 . 8 8 3}$ & $\mathbf{1 . 2 9 4 . 7 6 5}$ & $\mathbf{- 5 7 . 1 1 8}$ & $\mathbf{- 4 , 2 3 \%}$ \\
\hline
\end{tabular}

Fuente: Boletín Estadístico del Personal al Servicio de las Administraciones Públicas, Ministerio de Hacienda y Administraciones Públicas.

En ese sentido, uno de los «mitos» existentes comúnmente aceptados en la opinión pública afirmaba que, a consecuencia de la crisis, se estaban produciendo despidos masivos de empleados públicos ${ }^{31}$, incrementando así el creciente desempleo y la desprotección en áreas especialmente sensibles, como la sanidad y la educación.

Sin embargo, como hemos explicado anteriormente, la reducción y congelación de la tasa de reposición de efectivos se reveló como el instrumento más eficaz para la racionalización de estructuras de personal en la Administración Pública.

Así, y como se explica en el cuadro adjunto inferior, el análisis de la reducción de personal en el conjunto de las Administraciones Públicas demuestra que más del $63 \%$ de los empleados públicos que dejaron de formar parte de la Administración eran funcionarios, siendo el $37 \%$ restante personal laboral y que, de ellos, la mayoría de las bajas se produjeron por jubilación ordinaria o anticipada.

${ }^{31}$ Así lo afirmaba algún medio de comunicación, que sostenía que uno de los objetivos de la reforma laboral era facilitar el despido de empleados públicos: El Gobierno allana los despidos en Administración y empresas públicas, diario El País, 7 de agosto de 2012 , http://economia.elpais.com/economia/2012/08/06/actualidad/1344281713_807525.html.

También en el mismo periódico, "El Gobierno facilita los despidos colectivos en la Administración", diario El País, 30 de octubre de 2012, http://economia.elpais.com/economia/2012/10/30/actualidad/1351588770_264660.html. 
Es decir, que no se corresponde con la realidad el mito de que la crisis ha conllevado el despido masivo de empleados públicos sino, más bien, que la crisis ha reducido el volumen de las Administraciones Públicas con un porcentaje muy reducido de despidos, ya que ha operado principalmente a través de jubilaciones.

\begin{tabular}{|c|c|c|c|c|c|}
\hline ADMINISTRACIÓN & TIPOLOGÍA DE EMPLEADOS & 2012 & 2016 & Variación & Var. \% \\
\hline \multirow{4}{*}{$\begin{array}{l}\text { ADMINISTRACIÓN } \\
\text { PÚBLICA } \\
\text { ESTATAL }\end{array}$} & Funcionarios & 457.596 & 430.457 & -27.139 & $-5,93 \%$ \\
\hline & Personal Laboral & 113.063 & 86.936 & -26.127 & $-23,11 \%$ \\
\hline & Otro Personal & 11.202 & 10.408 & -794 & $-7,09 \%$ \\
\hline & TOTAL ADMINISTRACIÓN PÚBLICA ESTATAL & 581.861 & 527.801 & -54.060 & $-9,29 \%$ \\
\hline \multirow{4}{*}{$\begin{array}{c}\text { COMUNIDADES } \\
\text { AUTÓNOMAS }\end{array}$} & Funcionarios & 920.681 & 838.911 & -81.770 & $-8,88 \%$ \\
\hline & Personal Laboral & 143.869 & 133.295 & -10.574 & $-7,35 \%$ \\
\hline & \begin{tabular}{|l|} 
Otro Personal \\
\end{tabular} & 287.333 & 322.559 & 35.226 & $12,26 \%$ \\
\hline & TOTAL CCAA & 1.351 .883 & 1.294 .765 & -57.118 & $-4,23 \%$ \\
\hline \multirow{4}{*}{$\begin{array}{l}\text { ENTIDADES } \\
\text { LOCALES }\end{array}$} & Funcionarios & 220.573 & 207.791 & -12.782 & $-5,79 \%$ \\
\hline & Personal Laboral & 336.430 & 298.666 & -37.764 & $-11,22 \%$ \\
\hline & Otro Personal & 40.209 & 42.487 & 2.278 & $5,67 \%$ \\
\hline & TOTAL EELL & 597.212 & 548.944 & -48.268 & $-8,08 \%$ \\
\hline \multirow{4}{*}{ UNIVERSIDADES } & Funcionarios & 74.179 & 69.464 & -4.715 & $-6,36 \%$ \\
\hline & Personal Laboral & 69.839 & 71.205 & 1.366 & $1,96 \%$ \\
\hline & Otro Personal & 10.863 & 7.101 & -3.762 & $-34,63 \%$ \\
\hline & TOTAL UNIVERSIDADES & 154.881 & 147.770 & -7.111 & $-4,59 \%$ \\
\hline \multirow{4}{*}{$\begin{array}{c}\text { TOTAL } \\
\text { ADMINISTRACIONES } \\
\text { PÚBLICAS }\end{array}$} & Funcionarios & 1.673 .029 & 1.546 .623 & -126.406 & $-7,56 \%$ \\
\hline & Personal Laboral & 663.201 & 590.102 & -73.099 & $-11,02 \%$ \\
\hline & Otro Personal & 349.607 & 382.555 & 32.948 & $9,42 \%$ \\
\hline & TOTAL ADMINISTRACIONES PÚBLICAS & 2.685 .837 & 2.519 .280 & -166.557 & $-6,20 \%$ \\
\hline
\end{tabular}

Fuente: Boletín Estadístico del Personal al Servicio de las Administraciones Públicas.

En cuanto a la racionalización en el número de entes del conjunto de las Administraciones Públicas, se ha producido un descenso muy significativo de su volumen total, especialmente en el caso de las Comunidades Autónomas, donde se han reducido en más de un tercio.

Por subsectores, la Administración Estatal ha sido la administración con un descenso menor, de casi un $12 \%$ del total de existentes en $2010^{32}$ (54 entes menos), en parte debido a la reducida dimensión de la Administración del Estado en comparación con las Administraciones Territoriales. Por tipologías, el tipo de ente que más se ha reducido son las Fundaciones, con 19 menos, un 32,76\%, seguido de las sociedades mercantiles estatales y asimiladas, con 38 menos, un $20,54 \%$. No obstante, desde 2010 se ha incrementado el número de consorcios en un 46,67\%, habiendo pasado de 15 a 22 .

\begin{tabular}{|l|c|c|c|c|c|c|c|c|c|}
\hline \multicolumn{1}{|c|}{ INVENTARIO DE ENTES DEL SECTOR PÚBLICO ESTATAL 2010-2016 } \\
\hline \multicolumn{1}{|c|}{ TIPO DE ENTE } & 2010 & 2011 & 2012 & 2013 & 2014 & 2015 & $\begin{array}{c}\text { Avance } \\
2016\end{array}$ & $\begin{array}{c}\text { Var. 2010- } \\
2016\end{array}$ & $\%$ \\
\hline Agencias Estatales & 7 & 8 & 8 & 8 & 8 & 8 & 10 & 3 & $42,86 \%$ \\
\hline Consorcios & 15 & 25 & 21 & 20 & 15 & 20 & 22 & 7 & $46,67 \%$ \\
\hline Entidades públicas empresariales & 14 & 14 & 13 & 13 & 13 & 13 & 13 & -1 & $-7,14 \%$ \\
\hline $\begin{array}{l}\text { Fondos carentes de personalidad } \\
\text { jurídica }\end{array}$ & 22 & 24 & 21 & 22 & 24 & 25 & 25 & 3 & $13,64 \%$ \\
\hline Fundaciones & 58 & 51 & 48 & 46 & 42 & 39 & 39 & -19 & $-32,76 \%$ \\
\hline Organismos autónomos estatales & 68 & 67 & 64 & 64 & 60 & 59 & 59 & -9 & $-13,24 \%$ \\
\hline $\begin{array}{l}\text { Otras entidades estatales derecho } \\
\text { público }\end{array}$ & 56 & 56 & 59 & 54 & 55 & 57 & 57 & 1 & $1,79 \%$ \\
\hline $\begin{array}{l}\text { Sociedades mercantiles estatales } \\
\text { y asimiladas }\end{array}$ & 185 & 175 & 166 & 156 & 153 & 147 & 147 & -38 & $-20,54 \%$ \\
\hline $\begin{array}{l}\text { Entidades Gestoras y Servicios } \\
\text { Comunes de la Seguridad Social }\end{array}$ & 5 & 5 & 5 & 5 & 5 & 5 & 5 & 0 & $0 \%$ \\
\hline $\begin{array}{l}\text { Mutuas de Accidentes de Trabajo } \\
\text { y Enfermedades Profesionales de } \\
\text { la Seguridad Social }\end{array}$ & 24 & 24 & 24 & 24 & 24 & 23 & 23 & -1 & $-4 \%$ \\
\hline \multicolumn{1}{|c|}{ TOTAL } & 454 & 449 & 429 & 412 & 399 & 398 & 400 & -54 & $-11,89 \%$ \\
\hline
\end{tabular}

Fuente: Intervención General de la Administración del Estado, datos a julio de 2016.

\footnotetext{
${ }^{32}$ Entre 2012 y 2016 (provisional), la reducción ha sido de 29 entes, un 6,76\% menos.
} 
La racionalización del sector público instrumental de las Comunidades Autónomas sí ha sido, por el contrario, muy significativa, con una reducción, entre $2010^{33}$ y 2016 , de casi un $34 \%$ del total de entes existentes en 2010, 813 menos $^{34}$, muy cerca de los objetivos de disminución de entes, aprobados en los sucesivos Consejos de Política Fiscal y Financiera desde 2010.

En ese sentido, tras la culminación de los procesos planteados, el sector público instrumental del conjunto de las Comunidades Autónomas, -de las que se excluyen el País Vasco, aquellos en los que participan varias Comunidades Autónomas, y Ceuta y Melilla-, estaría compuesto por 1.498 entidades, un 37,69\% menos que a 1 de julio de 2010, y en niveles inferiores a 2003.

\section{RACIONALIZACIÓN DEL SECTOR PÚBLICO AUTONÓMICO 2010-2016}

\begin{tabular}{|c|c|c|c|c|c|c|}
\hline $\begin{array}{l}\text { COMUNIDAD } \\
\text { AUTÓNOMA }\end{array}$ & $\begin{array}{l}\text { DATOS } \\
1 / 7 / 2010\end{array}$ & $\begin{array}{c}\text { DATOS } \\
1 / 01 / 2016\end{array}$ & VARIACIÓN & PORCENTAJE & OBJETIVO & $\begin{array}{c}\text { ENTIDADES } \\
\text { POR } \\
\text { ELIMINAR }\end{array}$ \\
\hline Andalucía & 367 & 218 & -149 & $-40,60 \%$ & 207 & 11 \\
\hline Aragón & 119 & 92 & -27 & $-22,69 \%$ & 88 & 4 \\
\hline Asturias & 84 & 70 & -14 & $-16,67 \%$ & 70 & 0 \\
\hline Baleares & 181 & 73 & -108 & $-59,67 \%$ & 66 & 7 \\
\hline Canarias & 87 & 73 & -14 & $-16,09 \%$ & 69 & 4 \\
\hline Cantabria & 68 & 45 & -23 & $-33,82 \%$ & 42 & 3 \\
\hline Castilla la Mancha & 82 & 30 & -52 & $-63,41 \%$ & 30 & 0 \\
\hline Castilla y León & 86 & 59 & -27 & $-31,40 \%$ & 58 & 1 \\
\hline Cataluña & 495 & 374 & -121 & $-24,44 \%$ & 358 & 16 \\
\hline Extremadura & 83 & 63 & -20 & $-24,10 \%$ & 62 & 1 \\
\hline Galicia & 164 & 111 & -53 & $-32,32 \%$ & 101 & 10 \\
\hline Madrid & 190 & 146 & -44 & $-23,16 \%$ & 133 & 13 \\
\hline Murcia & 103 & 48 & -55 & $-53,40 \%$ & 42 & 6 \\
\hline Navarra & 93 & 53 & -40 & $-43,01 \%$ & 48 & 5 \\
\hline País Vasco & \multicolumn{6}{|c|}{ SIN DATOS } \\
\hline Rioja & 29 & 23 & -6 & $-20,69 \%$ & 23 & 0 \\
\hline Valencia & 173 & 113 & -60 & $-34,68 \%$ & 101 & 12 \\
\hline TOTAL & 2.404 & 1.591 & -813 & $-33,82 \%$ & 1.498 & 99 \\
\hline
\end{tabular}

Fuente: Informe sobre la reordenación del Sector Público Autonómico del Ministerio de Hacienda y Administraciones Públicas, enero 2016.

Por último, el sector público local ha experimentado también una notable reducción en su sector público administrativo e instrumental, como se observa en el cuadro inferior, con una disminución acumulada del $26 \%$ desde 2010 hasta 2015, un total de 1.562 entes menos.

Una reducción que, en un proceso inverso al operado en la Administración General del Estado, se ha concentrado fundamentalmente en los consorcios (casi un $40 \%$ menos), los organismos autónomos (34\% menos) y las fundaciones públicas ( $27 \%$ menos).

\begin{tabular}{|c|c|c|c|c|c|c|c|c|}
\hline \multirow[b]{2}{*}{ TIPO DE ENTE } & \multicolumn{8}{|c|}{ ENTIDADES QUE INTEGRAN EL SECTOR PÚBLICO LOCAL 2010-2015 } \\
\hline & 2010 & 2011 & 2012 & 2013 & 2014 & 2015 & $\begin{array}{c}\text { Var. 2010- } \\
2015\end{array}$ & $\%$ \\
\hline Organismos Autónomos & 1.580 & 1.426 & 1.265 & 1.168 & 1.105 & 1.043 & -537 & $-33,99 \%$ \\
\hline Entidades Públicas Empresariales & 56 & 57 & 57 & 56 & 54 & 55 & -1 & $-1,79 \%$ \\
\hline Consorcios & 939 & 756 & 689 & 625 & 576 & 571 & -368 & $-39,19 \%$ \\
\hline Sociedades & 2.195 & 2.112 & 2.029 & 1.922 & 1.824 & 1.748 & -447 & $-20,36 \%$ \\
\hline Fundaciones & 585 & 548 & 523 & 490 & 443 & 426 & -159 & $-27,18 \%$ \\
\hline Asociaciones & 624 & 613 & 609 & 586 & 571 & 574 & -50 & $-8,01 \%$ \\
\hline Total General & 5.979 & 5.512 & 5.172 & 4.847 & 4.573 & 4.417 & -1.562 & $-26,12 \%$ \\
\hline
\end{tabular}

Fuente: Ministerio de Hacienda y Administraciones Públicas, datos a 30 de septiembre de 2016. Recoge la evolución del sector público local referido a las entidades vinculadas o dependientes. No se incluyen las Entidades Locales a las que refiere el artículo 3 LrBRL, como municipios, provincias, islas, mancomunidades, Entidades de Ámbito Territorial Inferior al Municipio, comarcas, áreas metropolitanas u otras entidades que agrupen municipios.

33 Se toma como referencia el año 2010 debido a los acuerdos adoptados en los Consejo de Política Fiscal y Financiera, en concreto los Acuerdos de 22 de marzo de 2010, fecha en la que se estableció el compromiso inicial por parte de las Comunidades Autónomas, y de 17 de enero de 2012, donde se profundizó en el compromiso de racionalización del sector público autonómico.

34 De las 813 menos, 619 son bajas netas y 194 en estadios próximos a extinción, por estar en disolución, liquidación o cese de actividad. 
En conclusión, los procesos de reducción de los sectores instrumentales administrativos y no administrativos de las Administraciones Públicas han cumplido con creces con los objetivos pretendidos, siendo especialmente palpable este esfuerzo en las Administraciones Territoriales, que redujeron su volumen total de entes a los niveles de 2003, -en el caso de las Comunidades Autónomas-, y de finales de los años noventa del siglo pasado, -en el caso de las Entidades Locales-.

Por otro lado, y en lo relativo a la reducción de cargas administrativas ${ }^{35}$, destacan un gran número de medidas destinadas a reducir la burocracia en las relaciones de los ciudadanos y empresas con la Administración.

En ese sentido, y desde el año 2012 hasta el año 2015, se aprobaron cuatro Acuerdos de Consejo de Ministros en 2013, 2014 y 2015, con 145 medidas ${ }^{36}$ para reducir las cargas en procedimientos tramitados por los diferentes departamentos, con un ahorro estimado en más de mil quinientos millones de euros.

Además, se implantó el principio de compensación de cargas administrativas one in, one out ${ }^{37}$, -para evitar la proliferación de cargas-, y se aprobó el Manual de Simplificación y reducción de cargas administrativas $^{38}$, para homogeneizar criterios metodológicos relativos a la simplificación, sustentados en planes de acción anuales.

La conjunción de estas medidas, -aunque todavía, especialmente en las relaciones entre la Administración y las empresas, quede un largo recorrido-, supuso un gran avance en la reducción y limitación de las trabas y cargas administrativas, agilizando las relaciones de los ciudadanos y las empresas con los poderes públicos, y dinamizando la economía.

Por último, la Comisión para la Reforma de las Administraciones Públicas también impulsó notablemente la Administración Electrónica. El objetivo primordial era la modernización de la Administración desde la perspectiva de la eficacia y la eficiencia, introduciendo criterios de corresponsabilidad y calidad en un contexto de austeridad y, por lo tanto, de maximización de escasos recursos.

Con este planteamiento se creó, mediante el Real Decreto 695/2013, de 20 de septiembre, la Dirección de Tecnologías de la Información y las Comunicaciones de la Administración General del Estado (DTIC), para establecer una estrategia y unas líneas de acción comunes y racionalizar el uso de las Tecnologías de la Información y de las Comunicaciones en el Sector público Administrativo Estatal. Para ello, se definió un nuevo modelo de Gobernanza, aprobado por Real Decreto 806/2014 ${ }^{39}$, de 19 de septiembre, que es la base sobre la que se han de alinear todas las actuaciones de las Tecnologías de la Información y las Comunicaciones en la Administración General del Estado y sus organismos públicos.

35 Se consideran cargas administrativas aquellas actividades de naturaleza administrativa que deben llevar a cabo las empresas y los ciudadanos para cumplir con las obligaciones derivadas de la normativa. La reducción de cargas administrativas permite disminuir los costes de constitución o funcionamiento de las empresas y dedicar estos recursos liberados a actividades productivas, mejorando así la productividad y la competitividad de la economía. Se reducen con la eliminación de obligaciones innecesarias, en no requerir documentos o datos que obren en poder de las Administraciones, en reducir la frecuencia de petición de datos, reduciendo los plazos de tramitación de los procedimientos o posibilitando la presentación electrónica de solicitudes, comunicaciones y demás documentos, entre otras. Para el cálculo de los costes de una carga determinada, se multiplican tres factores: el coste unitario de cumplir con la carga, la frecuencia anual con la que debe realizarse y la población que debe cumplirla. La medición de los ahorros surgirá de la diferencia entre la situación de inicio y la situación tras haber reducido las cargas.

36 El 21 de junio de 2013 se aprobó el Séptimo Acuerdo para la reducción de las cargas administrativas y mejora de la regulación, que supuso la simplificación de 63 trámites con la Administración para permitir un ahorro anual estimado de más de 478 millones de euros. El 9 de enero de 2014 se aprobó el VIII Acuerdo de Reducción de cargas administrativas, con 19 medidas, con un ahorro total estimado de 74.843.814 euros. El 10 de julio de 2015 se aprobó el IX Acuerdo de Reducción de cargas administrativas, con 20 medidas, con un ahorro total estimado de 1.012.166.815 euros. El 27 de noviembre de 2015 se aprobó el X Acuerdo de Reducción de cargas administrativas, con 43 medidas.

37 La ley 14/2013, de 27 de septiembre, de apoyo a los emprendedores y su internacionalización ha establecido el principio de compensación de cargas, de forma que cuando una Administración Pública crea nuevas cargas administrativas para las empresas tiene que eliminar al menos una existente de coste equivalente (one in, one out). El Acuerdo de Consejo de Ministros de 30 de enero de 2015 estableció medidas para reforzar el seguimiento en la aplicación del principio "one in, one out», de forma que se garantice la compensación de cargas preferiblemente en cada departamento ministerial y en el plazo de un año.

38 El Manual de Simplificación y Reducción de Cargas Administrativas es una de las medidas propuestas por la CORA. El 9 de octubre de 2014 se publicó en el BOE el Acuerdo del Consejo de Ministros por el que se toma conocimiento del mismo. El objetivo era estudiar los procedimientos seleccionados y su pertinencia y simplificarlos en número de trámites, tiempo y coste. Los Ministerios deben identificar anualmente en un Plan de simplificación administrativa y reducción de cargas los procedimientos a revisar.

39 La publicación del RD 806/2014, permitió el desarrollo del nuevo modelo común de gobernanza en la Administración General del Estado y sus Organismos Públicos, con la aprobación de la primera Declaración de Servicios Compartidos (con catorce servicios de Tecnologías de la Información y Comunicaciones esenciales) y su Marco regulador y, por Acuerdo de Consejo de Ministros de 2 de octubre de 2015, el Plan de Transformación Digital de la Administración General del Estado y sus Organismos Públicos, -la llamada Estrategia TIC (2015-2020)-. 
Una medida que, tanto desde la perspectiva de los recursos como de la Gobernanza, ha servido para configurar un sistema mixto con áreas sectoriales específicas y una cartera de servicios compartidos de carácter obligatorio y sustitutivo. En ese sentido, destacan un buen número de iniciativas, como el servicio unificado de telecomunicaciones ${ }^{40}$, la plataforma Cl@ve ${ }^{41}$, el Punto General de Entrada de Facturas de la Administración del Estado $(\mathrm{FACe})^{42}$, la interconexión de registros y la eliminación del soporte papel ${ }^{43}$ o la carpeta ciudadana ${ }^{44}$.

En el escenario 2012-2016, se ha estimado en más de 3.000 millones de euros el impacto económico directo de estas medidas, tanto para la propia Administración como para los ciudadanos y el sector empresarial.

\subsection{Educación (en especial, la educación universitaria)}

En materia de Educación, además de las previsiones incluidas en la Ley de Presupuestos Generales del Estado, se aprobó una norma específica: el Real Decreto-ley 14/2012, de 20 de abril, de medidas urgentes de racionalización del gasto público en el ámbito educativo.

Como se indica en el Preámbulo, el objetivo común de las medidas incluidas en la norma es «proporcionar a las Administraciones educativas un conjunto de instrumentos que permitan conjugar los irrenunciables objetivos de calidad y eficiencia del sistema educativo con el cumplimiento de los objetivos de estabilidad presupuestaria y su ineludible reflejo en la contención del gasto público y en la oferta de empleo público».

Las medidas propuestas afectaron a todos los niveles educativos (universitarios y no universitarios) y combinaron disposiciones de carácter excepcional con otras de carácter estructural, buscando -como decía el Preámbulo de la norma- la mejora de la eficiencia del sistema educativo español.

Así, en la enseñanza no universitaria, el Real Decreto-Ley fijó el mínimo de horas que deben impartir los profesores en los centros docentes públicos, permitiendo la «flexibilidad» en el número de alumnos por clase (mientras se mantuviesen las restricciones en materia de incorporación de nuevo personal), prohibiendo la contratación de profesores sustitutos o interinos para cubrir bajas de menos de diez días y retrasando a 2014 la implantación de nuevos ciclos formativos de grado medio y superior.

Además, se eliminó la exigencia de ofertar al menos dos modalidades de Bachillerato, dejando a las Comunidades Autónomas, que son las competentes, un margen más amplio de decisión.

Por su parte, en el ámbito universitario se modificó la Ley Orgánica de Universidades (en concreto, el art. 68), para determinar el régimen de dedicación del personal docente e investigador de las Universidades: por un lado, la actividad docente a desarrollar (número de horas de docencia), que se gradúa en atención a la intensidad y excelencia de su actividad investigadora (medida en función del número de sexenios obtenidos en los correspondientes procesos de evaluación). Hasta ese momento, nada se decía sobre un mínimo o máximo de dedicación de los docentes, ni el reparto de esa dedicación entre la docencia y la investigación.

Además, se prevé la racionalización del mapa universitario y de la oferta de titulaciones, en función de los requisitos mínimos que se fijasen reglamentariamente, lo que permitiría a la Administración educativa autonómica tomar medidas para racionalizar los recursos, agrupando -por ejemplo- a los estudiantes de determinadas titulaciones cuando éstas se impartiesen en universidades que estuviesen en la misma localidad o en localidades vecinas o cercanas, y no tuviesen suficiente demanda en cada una de las universidades por

40 El Consejo de Ministros autorizó en octubre de 2014 la celebración de un contrato de servicios de telecomunicaciones en la Administración General del Estado. La red está siendo compartida por 12 ministerios y 64 organismos dependientes, dando servicio a más de 3.400 sedes de la Administración General del Estado en España y a 500 sedes en el extranjero en 200 ciudades de 125 países, con un ahorro estimado en la primera fase de 120 millones de euros, con un $43 \%$ de ahorro con respecto a lo gastado hasta el momento en contratos singulares para un mismo periodo.

41 Cl@ve es un servicio de identidad digital, con varios sistemas habilitados, que permite al ciudadano identificarse ante la Administración mediante un sistema único de claves concertadas.

42 Este Punto, al que se han adherido todas las Comunidades Autónomas, -menos el País Vasco-, y la inmensa mayoría de las Entidades Locales, ofrece a los proveedores un punto común para todas las Administraciones Públicas para la presentación de facturas electrónicas con todas las ventajas que ello representa: transparencia, ventanilla única, formato y codificación unificada.

43 Elimina el tránsito de papel entre oficinas, aumentando la eficiencia y eliminando los costes de manipulación y remisión del papel, gracias a la generación de copias auténticas electrónicas de la documentación presentada en los registros.

44 Permite consultar de manera personalizada y seguir en un único punto todos los expedientes de un ciudadano, así como sus notificaciones administrativas, los datos intermediados por la Administración, los asientos registrales y el acceso a servicios horizontales como apoderamientos o documentos. 
separado. Se trata, por tanto, de una opción que se dejaba abierta, buscando adaptar la oferta a la demanda y la eficiencia en la utilización de los recursos humanos y materiales ${ }^{45}$.

Asimismo, mediante la modificación del art. 81 de la LOU, se adecua el régimen económico y financiero de las universidades públicas al principio de estabilidad presupuestaria, que están obligadas a respetar. Por otro lado, se fijan umbrales en los precios públicos (modificando el párrafo primero del apartado b) del art. 81.3 de la ley), con el objeto de dejar la puerta abierta para que las Comunidades Autónomas, de acuerdo con las universidades, puedan aproximar gradualmente su cuantía a los costes de prestación del servicio, tomando asimismo en consideración el esfuerzo académico.

Esta reforma es la que, en la opinión pública, se interpretó como una subida de las tasas universitarias. En realidad, el Real Decreto Ley no establece ninguna subida, sino que abre una horquilla dentro de la cual las Comunidades Autónomas pueden decidir. De hecho, ha habido algunas Comunidades que no han modificado los precios de matrícula, mientras que otras han hecho uso de la opción que la modificación de la Ley les ofrecía. Esto ha generado, por un lado, un encarecimiento de las tasas universitarias en muchas Comunidades Autónomas, y además otro efecto negativo: la desigualdad en los precios públicos universitarios entre distintas Comunidades, que ha llegado a ser muy elevada, con diferencias de casi el triple entre algunas regiones y otras. En el curso 2015/16, por ejemplo, el precio medio por crédito más bajo en los estudios de Grado era el de Galicia (11,89 euros), y el más caro el de Cataluña (33,52 euros) ${ }^{46}$.

Por último, se somete expresamente la incorporación de personal de nuevo ingreso a la normativa básica en materia de Oferta de Empleo Público (OEP), dado que las mismas se incluyen en el artículo 22.Uno.a) de la Ley 39/2010, de Presupuestos Generales del Estado para el año 2012 (o artículo equivalente en las sucesivas leyes de presupuestos) así como en el artículo 23 de la misma Ley.

Así, el artículo 81.4 de la Ley Orgánica de Universidades, modificado por el Real Decreto Ley, dispone lo siguiente:
"Al estado de gastos corrientes, se acompañará la relación de puestos de trabajo del personal de todas las categorías de la Universidad especificando la totalidad de los costes de la misma e incluyendo un anexo en el que figuren los puestos de nuevo ingreso que se proponen. Los costes del personal docente e investigador, así como de administración y servicios, deberán ser autorizados por la Comunidad Autónoma, en el marco de la normativa básica sobre Oferta de Empleo Público. Asimismo, el nombramiento de personal funcionario interino y la contratación de personal laboral temporal por las universidades deberá respetar la normativa básica estatal en la materia».

Esta modificación puede parecer reiterativa, pero es muy relevante. El Real Decreto Ley 20/2011, de 30 de diciembre, ofrecía dudas interpretativas sobre su aplicación o no a las universidades públicas ${ }^{47}$. Por eso, hasta los meses de abril y mayo de 2012, las Universidades, a pesar de que teóricamente debían respetar la normativa básica sobre Oferta de Empleo Público, y aun estando vigente, en los últimos años, unas restricciones de personal de nuevo ingreso, derivadas de las limitaciones a la tasa de reposición que se había venido fijando en las leyes de presupuestos generales, no estaban respetando estas restricciones, o interpretaban erróneamente el cómputo de la tasa, en un supuesto ejercicio de una mal entendida autonomía universitaria ${ }^{48}$.

45 También se modificó la Ley Orgánica de Universidades (art. 30 bis) para facilitar la cooperación interuniversitaria para la impartición conjunta de titulaciones. Sin embargo, este artículo fue anulado por el Tribunal Constitucional en su STC 26/2016, de 18 de febrero, al resolver un recurso de inconstitucionalidad de la Junta de Andalucía, que había impugnado una buena parte del contenido del Real Decreto Ley 14/2012. (FJ 10 de la STC 26/2016, de 18 de febrero de 2016. Recurso de inconstitucionalidad 4528-2012. Interpuesto por el Consejo de Gobierno de la Junta de Andalucía en relación con diversos preceptos del Real Decreto-ley 14/2012, de 20 de abril).

46 MINISTERIO DE EDUCACIÓN, CULTURA Y DEPORTE, Datos y cifras del sistema universitario español. Curso 2015/2016, págs. 107 y ss.; los precios públicos de Máster pueden verse en las páginas 109 y siguientes. Disponible en: http://www.mecd.gob.es/ $\mathrm{dms} / \mathrm{mecd} / \mathrm{educacion}$-mecd/areas-educacion/universidades/estadisticas-informes/datos-cifras/datos-y-cifras-SUE-2015-16-web-.pdf.

47 Así lo ponen de relieve AMOEDO SOUTO, C., NOGUEIRA LÓPEZ, A, "Regateando hacia la excelencia. Tasa de reposición de efectivos y universidades públicas", en Revista Española de Derecho Administrativo, núm.157/2013, en las páginas 259-262; y SEPÚLVEDA GÓMEZ, M.; "La ciega aplicación de la tasa de reposición al personal docente e investigador de universidades públicas", Temas laborales núm. 127/2014. Págs. 264-267.

${ }_{48}$ Muy críticos con la aplicación de la tasa de reposición en las universidades son AMOEDO SOUTO, C., NOGUEIRA LÓPEZ, A, "Regateando hacia la excelencia. Tasa de reposición de efectivos y universidades públicas", en Revista Española de Derecho Administrativo, núm. 157/2013, págs. 249-281. Algunos se sorprendieron de que el Gobierno impugnase estas plazas, cuando las Universidades venían desde hace tiempo convocando plazas por encima de la tasa de reposición, sin que se hubiesen producido 
La inclusión de esta expresa referencia en la Ley Orgánica de Universidades reforzó (y aclaró) la vigencia de la normativa básica aplicable a los funcionarios y empleados públicos, también a las Universidades. De hecho, a partir de la entrada en vigor del Real Decreto Ley 14/2012, y de la Ley de Presupuestos de 2012, la Abogacía del Estado impugnó distintas convocatorias de plazas de acceso a cuerpos docentes universitarios, al entender que las universidades convocantes habían superado ya el porcentaje que les correspondía de tasa de reposición en ese año ${ }^{49}$. Muchos de estos recursos han llegado al Tribunal Supremo, que respaldó los argumentos de la Abogacía del Estado y confirmó la anulación de esas convocatorias $^{50}$.

La tasa de reposición, como hemos visto, ya se había comenzado a aplicar años antes ${ }^{51}$. En 2012, 2013 y 2014 se mantuvo la tasa de reposición «cero», exceptuando distintos ámbitos, entre ellos la educación universitaria y no universitaria ${ }^{52}$. Esto permitía un (escaso) $10 \%$ de tasa de reposición, porcentaje que en 2015 se elevó a un 50\% y en 2016 a un 100\%. La aplicación de esta tasa de reposición tuvo indudables efectos en la congelación del crecimiento de las plantillas, o en su reducción, tanto en la enseñanza no universitaria como en la universitaria, como puede comprobarse en la siguiente tabla:

\begin{tabular}{|c|c|c|c|c|c|c|c|}
\hline TOTAL EFECTIVOS & 2012 & 2013 & 2014 & 2015 & 2016 & $\begin{array}{c}\text { Var. 2012- } \\
2016\end{array}$ & Var. \% \\
\hline DOCENCIA NO UNIVERSITARIA & 549.996 & 527.469 & 527.948 & 531.030 & 539.716 & -10.280 & $-1,87 \%$ \\
\hline UNIVERSIDADES & 154.881 & 148.905 & 146.901 & 147.115 & 147.770 & -7.111 & $-4,59 \%$ \\
\hline
\end{tabular}

Fuente: Elaboración propia, a partir de los datos del Boletín Estadístico del Personal al Servicio de las Administraciones Públicas.

Sin embargo, la tasa de reposición, como instrumento de racionalización de estructuras y plantillas, debe tener, en todo caso, un carácter coyuntural y excepcional, circunscrito a un determinado periodo tem-

estas impugnaciones (cfr. NÚÑEZ LOZANO, M. C. y MALVÁREZ PASCUAL, L., "El cómputo de la tasa de reposición de efectivos en relación con las plazas de promoción del profesorado universitario: El análisis de un cambio de criterio carente de fundamento", Diario del Derecho, lustel, 16.09.2013. Para justificarlo, sostenían que cuando las plazas convocadas eran obtenidas por personal que ya estaba dentro de la Universidad, deberían considerarse plazas de promoción, y no debían computarse al no producirse ingreso de nuevos efectivos en la plantilla. Sin embargo, esta tesis no parece ser compartida por las múltiples sentencias del Tribunal Supremo, citadas en la nota 25.

${ }_{49}$ Sobre una de las sentencias recaídas en estos procedimientos contenciosos, vid. SEPÚLVEDA GÓMEZ, M.; "La ciega aplicación de la tasa de reposición al personal docente e investigador de universidades públicas", comentario a la Sentencia del Tribunal Superior de Justicia de Andalucía (Sevilla), Sala de lo Contencioso-Administrativo, de 30 de enero de 2014, en Temas laborales, núm. 127/2014, págs. 261-281.

50 Las sentencias son muchas, todas en el mismo sentido: Sentencias de la Sala de lo Contencioso Administrativo de 9 de marzo de 2015 (casación núm. 867/2014), 18 de mayo de 2015 (casación núm. 1690/2014), 9 de octubre de 2015 (casación núm. 2561/2014), 11 de octubre de 2015 (casación núm. 291/2015), 13 de octubre de 2015 (casación núm. 2573/2014), 15 de diciembre de 2015 (casación núm. 3686/2014); 23 y 29 de febrero de 2016 (casaciones núm. 198 y 241, de 2015); 2 y 9 de marzo de 2016 (casaciones núm. 250; 538 y 646, todas de 2015); 6 y 9 de mayo de 2016 (casaciones núm. 57 y 1165, de 2015), 15 de junio de 2016 (casación núm. 2684/2015), 21 de junio de 2016 (casación núm. 3309/2014), 8 de julio 2016 (casación núm. 1185/2015), 19 de julio de 2016 (casación núm. 1992/2015), 26 de septiembre de 2016 (casación núm. 208/2015), 30 de septiembre de 2016 (casación núm. 66/2015), 6 de octubre de 2016 (casación núm. 244/2015), 11 de octubre de 2016 (casación núm. 291/2015) y de 20 de octubre de 2016 (casación núm. 457/2015).

51 De 2003 a 2008 fue del 100\%. En 2009 se redujo al 30\% y a partir de 2010 se redujo al 10\%. El Programa de Estabilidad del Reino de España 2011-2014, aprobado en Consejo de Ministros el 29 de abril del año 2011, incidía (nuevamente, pues ya se había subrayado en el Programa de Estabilidad del Reino de España 2009-2013, así como en el Plan de Acción Inmediata 2010 y el Plan de Austeridad de la AGE 2011-2013) en la necesidad, para reducir el déficit, de mantener la congelación de los salarios del personal de todas las Administraciones Públicas durante el año 2011 (tras la rebaja del 5\% en 2010) y de aplicar una tasa de reposición de todo el personal de las Administraciones Públicas., durante los años 2011, 2012 y 2013, del 0\%, excepto el 10\% en determinados sectores prioritarios. El objetivo incluido en el Plan era el de conseguir, a finales del 2013, que las plantillas de las Administraciones Públicas se redujesen en un 7\%, que supondría un ajuste en el entorno de 0,8 puntos porcentuales del PIB hasta el año 2013. En el Programa Nacional de Reformas del Reino de España 2013, se hace nuevamente referencia a la reducción de gastos de personal, citando expresamente que los Presupuestos Generales del Estado de 2013 y 2014 mantendrán la congelación de la Oferta de Empleo Público.

52 Sobre la evolución del empleo en las Administraciones Públicas, como consecuencia de la aplicación de estas medidas, puede verse el trabajo de Antonio MONTESINOS, Javier J. PÉREZ y Roberto RAMOS, El empleo de las Administraciones Públicas en España: caracterización y evolución durante la crisis, Banco de España, Documentos Ocasionales, núm. 1402, 2014. Hay que resaltar que los datos utilizados no proceden de las mismas fuentes que las usadas en el presente trabajo, por eso en algunos casos hay ligeras variaciones en las cifras. 
poral, debiendo ser acompasada al contexto y circunstancias de cada momento, por lo que no puede ni debe prolongarse excesivamente en el tiempo ${ }^{53}$.

De mantenerse, a medio plazo provoca un envejecimiento de las plantillas, como sucede en la actualidad, lo que tanto en el ámbito universitario como en el no universitario provoca problemas cuando se acerca la edad de jubilación del personal docente, no sólo porque impide la entrada de personal joven que refresca la plantilla, sino porque la incorporación de personal es inferior a las bajas sufridas a causa de las jubilaciones.

Estas situaciones, además, conllevan una sobrecarga de trabajo en las distintas áreas y departamentos, que a veces se solucionan con contrataciones temporales de profesores a tiempo parcial, que en condiciones normales la Universidad no habría planificado, porque suponen soluciones coyunturales que impiden una planificación estratégica adecuada. Se respetaría mejor la autonomía de las universidades si, en lugar de establecer una tasa de reposición sobre puestos docentes individuales, se determinase un límite de gasto dentro del cual las Universidades pudiesen tomar decisiones y planificar un desarrollo racional y adecuado de su plantilla de profesorado.

\subsection{Sanidad}

Las medidas que afectaron al ámbito de la sanidad se incluyeron en el Real Decreto-ley 16/2012, de 20 de abril, de medidas urgentes para garantizar la sostenibilidad del Sistema Nacional de Salud y mejorar la calidad y seguridad de sus prestaciones.

Como en los casos anteriores, vamos a fijarnos exclusivamente en las cuestiones que afectan a reformas que afectan directamente a las Administraciones Públicas, sin repasar, porque no es el objeto de este trabajo, las medidas exclusivamente económicas o referidas a cuestiones coyunturales sobre determinadas prestaciones, como las que preveían un copago de algunas de ellas por parte de los ciudadanos beneficiados (por ejemplo, medidas sobre el pago de prótesis ambulatoria o transporte sanitario no urgente; sobre las técnicas, tecnologías y procedimientos no incluidas en los «servicios comunes»; las conocidas como «copago farmacéutico»: o la exclusión de la financiación pública en la compra de algunos fármacos indicados para el tratamiento de síntomas menores). Tampoco nos detendremos en analizar la polémica sobre las restricciones de la atención sanitaria a los extranjeros ${ }^{54}$, a los que se exige que regularicen su tarjeta sanitaria, las medidas sobre el «turismo sanitario» o sobre los nuevos requisitos que se exigen a los jóvenes de más de 26 años para seguir disfrutando de la sanidad pública.

Las medidas que sí tienen interés para nosotros, por referirse a la racionalización de los recursos humanos, se recogen en el Capítulo $V$ del Real Decreto Ley. Como se indica en el preámbulo, «los fondos destinados a financiar los recursos humanos en los servicios de salud suponen la partida más importante de sus presupuestos. La diversidad de normas reguladoras, la complejidad organizativa de titulaciones, categorías y situaciones laborales de los más de 600.000 trabajadores de los 17 servicios de salud ha ido generando una gran variabilidad interpretativa de las normas reguladoras, que se demuestran como verdaderas barreras para el desarrollo de los planes de eficiencia y ordenación que las comunidades autónomas están desarrollando en el marco económico de crisis actual y para la libertad de movimientos de los trabajadores entre servicios de salud».

Por tanto, en un contexto de crisis económica como el que se vivía en 2012, era especialmente necesario definir homogéneamente para todo el Sistema Nacional de Salud la regulación de aspectos vinculados a las categorías profesionales, los criterios generales reguladores del sistema retributivo o de la acción social.

Por un lado, se modifica la Ley 44/2003, de 21 de noviembre, de ordenación de las profesiones sanitarias, en lo relativo a la regulación de las Áreas de Capacitación Específica, la clarificación de las competen-

${ }^{53}$ Existe mucha bibliografía crítica con la aplicación de la tasa de reposición. En este sentido, puede verse el trabajo citado de AMOEDO SOUTO, C., NOGUEIRA LÓPEZ, A, "Regateando hacia la excelencia. Tasa de reposición de efectivos y universidades públicas", en Revista Española de Derecho Administrativo, núm.157/2013, especialmente en las páginas 251-252, aunque también en el resto del artículo.

${ }^{54}$ Sobre esta cuestión puede verse: DELGADO DEL RINCÓN, Luis, "El derecho a la asistencia sanitaria de los inmigrantes irregulares: reflexiones sobre la reforma introducida por el Real Decreto-ley 16/2012, de 20 de abril”, en Revista de Estudios Politicos, núm. 163, 2014, págs. 189-231; APRELL LASAGABASTER, C., "El derecho a la asistencia sanitaria de los extranjeros: los efectos del Real Decreto-ley 16/2012, de medidas urgentes para garantizar la sostenibilidad del Sistema Nacional de Salud y mejorar la calidad y seguridad de las prestaciones", en Revista General de Derecho Administrativo, 32, 2013. 
cias en la formación de especialistas, la resolución de las solicitudes de acreditación de centros docentes y su auditoría y evaluación.

Asimismo, se crea un Registro Estatal de Profesionales Sanitarios, que se trata de una herramienta imprescindible para garantizar la información a la población y a las instituciones de la situación de los profesionales desde los diferentes aspectos que configuran la práctica profesional. Ya existían registros autonómicos y colegiales, pero no son suficientes para garantizar la necesaria planificación y control de los recursos humanos con los que cuenta el sistema sanitario. Este registro estatal, al posibilitar una conexión con los registros autonómicos en tiempo real, permitirá que los datos de especial necesidad estén disponibles de modo inmediato.

Por otro lado, se incluyen medidas para garantizar la movilidad de los profesionales, mediante la elaboración de un catálogo homogéneo de categorías profesionales donde se establezcan las necesarias equivalencias. Una de las virtualidades de este catálogo es la de permitir que los profesionales puedan acceder a plazas vacantes de otros servicios de salud, mejorando la calidad de la asistencia, ya que esas plazas no van a ser objeto de provisión reglada mediante la convocatoria de procesos selectivos, al encontrarse congelada la oferta de empleo público.

Todas estas medidas, unidas a la tasa de reposición incluida cada año en los Presupuestos Generales del Estado, han conseguido, en el ámbito de los recursos humanos, limitar el crecimiento del número de efectivos. Los distintos programas de estabilidad del Reino de España, desde el año 2009, han incluido este objetivo.

Ya hemos visto que el programa de Estabilidad 2011-2014 preveía la aplicación de una tasa de reposición de todo el personal de las Administraciones Públicas: en 2011, 2012 y 2013, del 0\%, excepto el 10\% en determinados sectores prioritarios (entre ellos, Sanidad y Educación). El mismo criterio se mantiene en el Programa Nacional de Reformas 2013 y en 2014. En 2015 se amplió el porcentaje de excepción al 50\%, y en los Presupuestos Generales de 2016 se volvió a ampliar hasta el $100 \%{ }^{55}$ en los sectores excepcionados, y se estableció para todos los demás sectores una tasa del $50 \%{ }^{56}$.

La evolución de efectivos desde 2012 a 2016 ha sido la siguiente:

\begin{tabular}{|c|c|c|c|c|c|c|c|}
\hline TOTAL EFECTIVOS & 2012 & 2013 & 2014 & 2015 & 2016 & \multicolumn{1}{c|}{ Var. 2012-2016 } & Var. \% \\
\hline INSTITUCIONES SANITARIAS & 505.185 & 492.679 & 476.689 & 505.165 & 480.626 & $\mathbf{- 2 4 . 5 5 9}$ & $\mathbf{- 4 , 8 6 \%}$ \\
\hline
\end{tabular}

Fuente: Elaboración propia, a partir de los datos del Boletín Estadístico del Personal al Servicio de las Administraciones Públicas.

Puede apreciarse, por tanto, un descenso del número de funcionarios y empleados públicos, en esas cifras globales, que incluyen los dependientes de la Administración General del Estado y los de las administraciones autonómicas.

\subsection{Dependencia}

Nos ha parecido interesante incluir una mención a la Dependencia en este trabajo no sólo porque se ha convertido ya en una política más del Estado Social, sino también porque su puesta en marcha coincidió con el inicio de la crisis económica.

Además, y por otro lado, se trata de un ámbito en el que las previsiones económicas iniciales, incluidas en la Memoria económica de la Ley, no se han verificado en la realidad ${ }^{57}$. Por ello, vamos a analizar primero algunas reformas incluidas en el sistema, y después el problema de la financiación, una de las materias que, sin duda, deberá ser objeto de negociación en la elaboración del nuevo sistema de financiación autonómico.

\footnotetext{
55 Véase, en ese sentido, el artículo 20.Uno, 2, de la Ley de Presupuestos Generales del Estado para 2016.

${ }_{56}$ Así lo establecía el art. 20.Uno, 3, de la Ley de Presupuestos Generales del Estado para 2016: «En los sectores y Administraciones no recogidos en el apartado anterior, la tasa de reposición se fijará hasta un máximo del 50 por ciento».

57 Sobre la Ley de Dependencia puede verse SEMPERE NAVARRO, A. (coord.) Comentario sistemático a la Ley de la Dependencia. Ley 39/2006, de 14 de diciembre, de promoción de la autonomía personal y atención a las personas en situación de dependencia y normas autonómicas, Aranzadi, Pamplona, 2008. También resulta interesante, para tener una breve visión comparada de la atención a la Dependencia en otros países, y constatar que la pretensión de universalidad de nuestra Ley es muy avanzada, y no es la habitual en países de nuestro entorno, el trabajo de LÓPEZ CASASNOVAS, G. y FANER AGUILÓ, J., "Consideraciones para la reforma y mejora de la aplicación de la Ley de Dependencia a partir de la observación de sistemas comparados", en Papeles de Economía Española, núm. 129, 2011, monográfico dedicado a «Aspectos económicos y sociales de la dependencia», págs. 149-156.
} 


\section{a) Las reformas en el Sistema para la Autonomía y Atención a la Dependencia}

Las reformas en materia de Dependencia se incluyeron, fundamentalmente, en el Real Decreto-ley 20/2012, de 13 de julio, de medidas para garantizar la estabilidad presupuestaria y de fomento de la competitividad.

En el apartado IV del preámbulo se afirmaba que «Los datos estructurales y las cifras más significativas del gasto en materia de dependencia, (...) muestran que debe corregirse una situación que pone en riesgo la sostenibilidad del Sistema que, además, ha supuesto consecuencias perjudiciales para el empleo y la viabilidad de los sectores productivos de servicios relacionados con la dependencia».

A continuación, se subraya, todos (Gobierno y Comunidades Autónomas, en el seno del Consejo Territorial del Sistema para la Autonomía y Atención a la Dependencia) «han expresado la necesidad de acometer mejoras para asegurar la sostenibilidad del Sistema, no solo a través de los correspondientes instrumentos normativos, sino también impulsando buenas prácticas y poniendo en común experiencias, siempre con base en el diálogo y contando con todas las administraciones públicas, los grupos políticos y cuantas asociaciones y entidades actúan en el ámbito de la promoción de la autonomía y atención a las personas en situación de dependencia». Se refiere así, básicamente, al acuerdo adoptado por las Comunidades Autónomas y el Estado en el Consejo Territorial de Servicios Sociales y del Sistema para la Autonomía y Atención a la Dependencia (SAAD), el 10 de julio de 2012, que contiene una serie de medidas para la mejora y sostenibilidad del sistema de atención a la dependencia ${ }^{58}$.

Estas medidas se incluyen en el Real Decreto Ley, y siguen la senda iniciada con el Real Decreto-ley

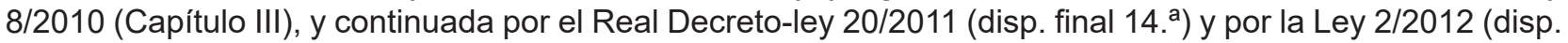
final ${ }^{a}{ }^{a}$ ). En resumen, se refieren $a^{59}$ :

- La refundición de la Conferencia Sectorial de Asuntos Sociales (suprimida por disposición adicional 9. ${ }^{\text {a }} 2$ del Real Decreto Ley) y del Consejo Territorial del Sistema para la Autonomía y Atención a la Dependencia en un solo órgano denominado Consejo Territorial de Servicios Sociales y del Sistema para la Autonomía y Atención a la Dependencia.

- El establecimiento de una nueva estructura, que supone el mantenimiento de los tres grados en los que se clasifica la situación de dependencia y la supresión de la clasificación de los grados de dependencia en dos niveles en función de la autonomía de las personas y de la intensidad del cuidado que requiere (se suprime el art. 26.2 de la Ley de Dependencia), desapareciendo, en consecuencia, su referencia en los preceptos en que se mencionaba.

- La modificación de la prestación económica para cuidados en el entorno familiar y apoyo a cuidadores no profesionales en un doble sentido:

- Reducción de su cuantía.

- Modificación de los efectos retroactivos:

- Estas prestaciones, desde el 15 de julio de 2012, dejarán de producir efectos retroactivos para los que en esa fecha no hayan comenzado a percibirlas todavía, si bien conservarán el derecho a percibir las cuantías que, en concepto de efectos retroactivos, hayan sido ya devengadas hasta dicho momento.

- Las cuantías en concepto de efectos retroactivos de estas prestaciones para los casos en que éstos se hayan generado desde la fecha de la solicitud, podrán ser aplazadas y su abono periodificado en pagos anuales de igual cuantía.

- El cambio en la situación de los cuidadores no profesionales, hasta ese momento incluidos obligatoriamente en el campo de aplicación del Régimen General de la Seguridad Social y en situación asimilada al alta. A partir del 15 de julio de 2012, la suscripción del convenio especial regulado como obligatorio en el Real Decreto 615/2007, de 11 de mayo, por el que se regula la Seguridad Social de los cuidadores de las personas en situación de dependencia, pasa a ser voluntaria (disposición adi-

58 Acuerdo publicado en el BOE núm. 185 de 3 de agosto de 2012.

59 Un comentario a estas reformas, aunque matizable en muchos aspectos, puede verse en Martín Azcano, E. M., "Efectividad del sistema para la autonomía y atención a la dependencia tras las reformas operadas con motivo de la crisis económica", en Actualidad Civil, núm. 3, Sección Persona y derechos / A fondo, Marzo 2016, Editorial LA LEY. 
cional 8. $\left.{ }^{a} \mathrm{RDL}\right)^{60}$. A 31 de diciembre de 2016 , el número de cuidadores con convenio era de $9.753^{61}$.

- Se redefine la prestación económica de asistencia personal (para contribuir a la contratación de una asistencia personal que facilite al beneficiario el acceso a la educación y al trabajo, así como una vida más autónoma), que se extiende ahora a todos los dependientes en cualquiera de sus grados (hasta ahora se dirigía solo a las personas con gran dependencia) (art. 19 de la Ley de Dependencia).

- Se modifica el servicio de ayuda a domicilio, de modo que las entidades o empresas acreditadas para esta función, podrán prestar servicios relacionados con la atención personal o con la atención de las necesidades domésticas o del hogar, siempre que lo hagan conjuntamente con los enunciados en primer lugar (hasta ahora se podían prestar aisladamente limitándose a la atención de las necesidades domésticas). (art. 23 de la Ley de Dependencia).

- Se establece un régimen de incompatibilidades de las prestaciones (nuevo art. 25 bis de la Ley de Dependencia) conforme al cual algunas prestaciones económicas y algunos servicios serán incompatibles entre sí, con excepciones.

- Se modifica el calendario de aplicación de los servicios y prestaciones de cobertura a la situación de dependencia (disposición final 1. ${ }^{a} .1$ de la Ley de Dependencia), que finalizará el 1 de julio de 2015, con la incorporación al sistema de quienes hayan sido valorados en el Grado I, Nivel I o de Dependencia Moderada.

- Por último, el art. 22.3 dispone que el nivel mínimo de protección garantizado en las Comunidades Autónomas se asignará considerando el número de beneficiarios, el grado de dependencia y la prestación reconocida. Además, hasta que se regule reglamentariamente, se fija la aportación de la Administración General del Estado para la financiación del nivel mínimo de protección previsto en el artículo 9 de la Ley de Dependencia (disposición transitoria 11. ${ }^{a} \mathrm{RDL}$ ) y la intensidad de protección de los servicios del catálogo (disposición transitoria 12. ${ }^{a}$ del Real Decreto Ley).

Cabe destacar, para lo que aquí nos interesa, algunas cuestiones. En primer lugar, la Ley 39/2006 preveía que la prestación económica para cuidados en el entorno familiar y apoyo a cuidadores no profesionales se reconocería «excepcionalmente». Es decir, lo normal serían las llamadas «prestaciones de servicios».

Pues bien, el propio Tribunal de Cuentas constató, en 201362, que «el carácter excepcional de estas prestaciones no se ha cumplido, dado que, al final de cada ejercicio, las prestaciones económicas han su-

60 Se trata de un convenio especial con la Tesorería General de la Seguridad Social, para computarel periodo de tiempo durante el que desarrollen tal función como cotizado a los efectos de determinadas prestaciones (jubilación, incapacidad permanente, o muerte y supervivencia). El problema era que las cuotas derivadas de ese convenio debían haber corrido exclusivamente por cuenta de la Administración General del Estado (ni las Comunidades Autónomas ni los propios cuidadores tenían que pagar nada. La prestación económica por cuidados en el entorno familiar fue la mayoritariamente reconocida en los primeros años de aplicación de la Ley, por lo que las cantidades devengadas en este concepto desbordaron todas las previsiones, y la Administración General del Estado no pudo pagar las correspondientes cuotas. En 2012 la situación de la Dependencia era muy complicada y poco viable desde el punto de vista financiero, y a ello se unía esta deuda, que superaba los mil millones de euros, con la Tesorería General de la Seguridad Social (el Acuerdo para la mejora del sistema aprobado por el Consejo Territorial dice que la suscripción de esos convenios generó un gasto de 1.047 millones de euros a cargo de la Administración General del Estado. BOE, núm. 185, 3 agosto 2012, pág. 55.659.). Además, la medida se reveló como ineficaz, puesto que esas altas en la Seguridad Social no suponen creación de empleo, puesto que la relación que une a los cuidadores con las personas en situación de dependencia no es de carácter laboral, sino familiar (en este sentido, son interesantes las Evaluaciones anuales del sistema, por ejemplo la de 2013, publicada en el BOE Evaluación anual correspondiente al ejercicio 2013, BOE, núm. 197, 14 agosto 2014, especialmente las págs. 65.387 y 65.388). Por eso, fue el propio Consejo Territorial el que sugirió una revisión en profundidad del sistema de afiliación, alta y cotización de los cuidadores en el entorno familiar, y también aprobó promover la progresiva profesionalización de los cuidados, dentro del sistema de atención a la dependencia. Este acuerdo del Consejo Territorial es el que se ve recogido por el Real Decreto-Ley 20/2012, que, en su disposición adicional 8. ${ }^{a}$. Asimismo, la disposición transitoria 13. ${ }^{a}$ del mencionado Real Decreto-Ley establece que los que ya estuviesen vigentes conforme al Real Decreto 615/2007, de 11 de mayo, se extinguiesen con efectos de 31 de agosto de 2012, salvo que el suscriptor solicitase su mantenimiento antes del 1 de noviembre de 2012. En este supuesto, entre el 1 de septiembre y el 31 de diciembre de 2012, la cotización a la Seguridad Social tendría una reducción del 10\% en el total de la cuota a abonar, siendo a cargo de la Administración General del Estado el $5 \%$ del total de la cuota y a cargo del cuidador informal el $85 \%$ restante. A partir de enero del 2013 , la satisfacción integra de la cuota correspondería al suscriptor del convenio.

61 Puede consultarse el dato en la web del IMSERSO: http://www.dependencia.imserso.es/InterPresent2/groups/imserso/documents/binario/im_062035.pdf.

62 Informe número 977, de Fiscalización de la gestión económico-financiera y de la aplicación de la Ley 39/2006, de 14 de diciembre, de Promoción de la Autonomía Personal y Atención a las personas en situación de dependencia. Disponible en: http://www. congreso.es/docu/inf_fiscTC/251-24.pdf. También se pone de relieve esta desviación sobre las previsiones iniciales en León, M., "Ideas, políticas y realidad: análisis crítico de la Ley de Dependencia", en Papeles de Economía Española, núm. 129, 2011, págs. 170-181. 
perado a las prestaciones de servicios». De manera que, según el Tribunal, «si no se invierte esta tendencia (...), el SAAD podría acabar convirtiéndose más en un sistema de subsidios que en una red asistencial de servicios, lo que podría no garantizar una atención de calidad ni la autonomía personal de las personas en situación de dependencia, finalidad última de la Ley 39/2006».

Para corregir esta situación, el Real Decreto 1050/2013, de 27 de diciembre, introduce, como ya se ha señalado anteriormente, el tipo de prestación concedida como variable para calcular el nivel mínimo de protección, primando la prestación de servicios sobre la prestación económica por cuidados en el entorno familiar.

La tendencia se ha conseguido revertir, de manera que a 31 de diciembre de 2016, las prestaciones económicas (de los 3 tipos posibles) suponían un $42,83 \%$ del total (frente al $51,96 \%$ recogido en el informe del Tribunal) ${ }^{63}$. Si solamente tenemos en cuenta las Prestaciones Económicas para Cuidados en el Entorno Familiar, suponen un $33,79 \%$ (un $45,53 \%$ en 2011 ), frente al $66,21 \%$ de Servicios Profesionales, lo que muestra una reducción sustancial de la primera en favor de la segunda, acercándose más a lo previsto en la Ley. En concreto, se puede observar un aumento y una consolidación en todos los servicios profesionales, sean de ayuda a domicilio, de centro de día o de atención residencial, así como de las prestaciones económicas vinculadas al servicio y de asistencia personal, lo que contribuye a la generación de nuevos puestos de trabajo ${ }^{64}$.

La excesiva prevalencia de las prestaciones económicas por cuidados en el entorno familiar ha sido causa, además, de que tampoco se cumplieran las expectativas de generación de empleo que preveían los estudios preparatorios de la ley. Por ello, en la nueva normativa se da prioridad a la profesionalización, lo cual ha tenido una positiva repercusión en la creación de empleo. Desde el 31 de diciembre de 2011, se ha incrementado el número de afiliaciones a la Seguridad Social en 53.469 personas, Ilegando a la cifra de 391.589 personas afiliadas a 31 de diciembre de $2016^{65}$.

En definitiva, estas reformas parecen estar dando sus frutos. No obstante, el gran problema pendiente de resolver es el de la financiación, en el que nos centraremos en el siguiente apartado.

\section{b) La financiación}

La primera cuestión a destacar es que, aunque algunas Comunidades Autónomas plantearon dudas competenciales, el Tribunal Constitucional confirmó la constitucionalidad del Real Decreto-Ley 20/2012, y la del propio modelo de financiación. En la STC 18/2016, de 4 de febrero ${ }^{66}$, que resuelve el recurso de inconstitucionalidad interpuesto por la Generalitat catalana contra dicha norma, se avala su contenido y, por lo tanto, las medidas de mejora de la Ley 39/2006, de 14 de diciembre, de Promoción de la Autonomía Personal y Atención a las personas en situación de Dependencia.

El Tribunal Constitucional (TC) considera que el legislador estatal no ha rebasado el ámbito de las funciones que le corresponden en la apreciación de aquellas circunstancias socioeconómicas que inevitablemente condicionan la adecuación y actualización del Sistema para la Autonomía y Atención a la Dependencia (SAAD), cuyo nivel de cobertura se ve condicionado por las disponibilidades financieras y la necesidad de equilibrio en el reparto del gasto público, ya que el Estado viene obligado a conjugar un equilibrio entre la

63 Los datos a fecha 31 de diciembre de 2016 pueden comprobarse en la página web del IMSERSO: http://www.dependencia. imserso.es/InterPresent2/groups/imserso/documents/binario/estsisaad20161231.pdf.

64 En las estadísticas del Tribunal de Cuentas, estas dos prestaciones se consideran económicas, y no de servicios profesionales, a pesar de que en la Resolución de 13 de julio de 2012, de la Secretaría de Estado de Servicios Sociales e Igualdad, por la que se publica el Acuerdo del Consejo Territorial del Sistema para la Autonomía y Atención a la Dependencia para la mejora del SAAD, se establecen nuevos criterios de asignación del nivel mínimo de protección, de manera que se pondere positivamente la prestación de servicios frente a la prestación económica para cuidados en el entorno familiar. De esta manera, tanto la prestación económica vinculada al servicio como la prestación económica de asistencia personal se equiparan a servicios, en contraposición a la prestación económica para cuidados en el entorno familiar.

65 Información disponible en la página web del IMSERSO: http://www.dependencia.imserso.es/dependencia_01/documentacion/ estadisticas/est_inf/otros_inf/id/index.htm.

66 https://www.boe.es/diario_boe/txt.php?id=BOE-A-2016-2335. Posteriormente, el TC reafirma la constitucionalidad del Real Decreto Ley en la STC 36/2006, de 3 de marzo, dictada en el recurso de inconstitucionalidad interpuesto por el Parlamento de Navarra en relación con diversos preceptos del Real Decreto-ley 20/2012, de 13 de julio, y expresamente considera adecuadas las disposiciones legales estatales relativas a la ayuda domiciliaria y régimen de compatibilidad de prestaciones. Puede consultarse esta sentencia en: https://www.boe.es/diario_boe/txt.php?id=BOE-A-2016-3402. 
cobertura universal de las prestaciones de atención a la dependencia, la suficiencia de la atención ofrecida y la propia sostenibilidad financiera del SAAD ${ }^{67}$.

Nuestro Alto Tribunal considera también, en esta sentencia, que el Gobierno está cumpliendo con la obligación prevista en la Ley sobre la financiación de la atención a la Dependencia, es decir, que se está aportando al menos aporte la misma cantidad que cada una de las Comunidades Autónomas ${ }^{68}$, a pesar de que no se haya seguido aportando lo previsto anteriormente por la vía del nivel acordado.

La estructura de la financiación del SAAD es compleja y no siempre se entiende y explica bien. Las aportaciones desde los Presupuestos Generales del Estado para garantizar la financiación de la Atención a la Dependencia, en igualdad de condiciones para todo el conjunto del territorio, están recogidas en dos leyes:

- La Ley 39/2006, de 14 de diciembre, de Promoción de la Autonomía Personal y Atención a las Personas en Situación de Dependencia. Recoge la financiación finalista del Sistema, así como las obligaciones al respecto asumidas tanto por la Administración General del Estado, las Comunidades Autónomas y las personas beneficiarias de las prestaciones.

- La Ley 22/2009, de 18 de diciembre, por la que se regula el Sistema de financiación de las Comunidades Autónomas de Régimen Común, donde se establece que las Comunidades Autónomas percibirán a partir del ejercicio 2009 unos recursos adicionales en función del número de personas potencialmente dependientes y del número de personas reconocidas como dependientes con derecho a prestación, registradas en el Sistema de Información del SAAD (SISAAD).

A la financiación del nivel mínimo hay que añadir, por tanto, como confirma el Informe 1.035 de Fiscalización del Tribunal de Cuentas, de 29 de mayo de $2014^{69}$, la financiación adicional que contemplan los artículos 5 y 6 de la Ley 22/2009, de Financiación de las Comunidades Autónomas de Régimen Común (LOFCA), para garantizar el acceso a los servicios públicos de Dependencia, junto con la Sanidad y la Educación, en igualdad de condiciones y con independencia, también, del lugar donde resida la persona dependiente.

Desde que la Ley de Dependencia fuera aprobada en 2007, las Comunidades Autónomas demandaron un aumento en la financiación incluida los Presupuestos Generales del Estado, para poder implantar la Ley de forma adecuada y según los criterios y principios contenidos en ella. De hecho, durante los dos primeros años de vigencia de la Ley de Promoción de la Autonomía Personal y Atención a las Personas en situación de Dependencia y hasta muy avanzado el año 2009, el único instrumento de financiación desde los Presupuestos Generales del Estado era la financiación específica prevista en la Ley 39/2006.

Sin embargo, las Comunidades Autónomas solicitaron en el Consejo de Política Fiscal y Financiera una financiación adicional para continuar con la implantación de la Ley. Esto se reflejó en el Acuerdo 6/2009 de este Consejo ${ }^{70}$, acuerdo que se trasladó a la nueva Ley 22/2009, de financiación autonómica. De este modo, las Comunidades Autónomas, además de pedir una nueva financiación para la atención a la Dependencia, solicitaron que ésta se encauzase por la vía de la financiación LOFCA, si bien teniendo en cuenta los crite-

67 En el Fundamento Jurídico 8 de la Sentencia, el Tribunal Constitucional señala que «los datos derivados de la evaluación de la misma - de la Ley de Promoción de la Autonomía y Atención a las Personas en situación de Dependencia-, a los cinco años de su vigencia, muestran que debe corregirse una situación que pone en riesgo la sostenibilidad del Sistema que, además, ha supuesto consecuencias perjudiciales para el empleo y la viabilidad de los sectores productivos de servicios relacionados con la dependencia». Para añadir que «la intensidad de los problemas detectados y el alcance estructural que precisan la medidas correctoras exigen su inmediata aplicación para una correcta evolución del Sistema. La demora en su aprobación, dada la propia evolución inercial del Sistema, agudizaría sus problemas de cohesión, equidad y financiación, tornándose las medidas propuestas más difíciles de aplicar».

68 Para el Tribunal Constitucional, «el art. 32.3, segundo párrafo de la Ley 39/2006, de 14 de diciembre, únicamente exige que la aportación autonómica sea, al menos igual a la de la Administración General del Estado, en el segundo nivel de protección, lo que implica que, suspendidos los convenios mediante los que se financiaba ese segundo nivel, la aportación autonómica en aplicación de dicho precepto no es ya obligatoria, por lo que, al menos en teoría, la reducción de la aportación estatal es susceptible de producir el correlativo efecto de reducción de la aportación autonómica, sin que, por esa vía, se produzca irremediablemente un incremento de gasto autonómico». Y añade "Ahora bien, si esa reducción autonómica se produce o no, es una cuestión que corresponde decidir a cada Comunidad Autónoma en el ejercicio de su competencia en materia de asistencia social. Pero no puede pretenderse que el hecho de que una determinada Comunidad Autónoma considere necesario o conveniente mantener las prestaciones del SAAD en un determinado nivel, superior al mínimo garantizado por el Estado, implique necesariamente el mantenimiento de las aportaciones estatales a la financiación del SAAD».

69 Tribunal de Cuentas, Informe de fiscalización sobre las medidas de gestión y control adoptadas por las Comunidades Autónomas para la adecuada aplicación de la Ley 39/2006, de 14 de diciembre, de promoción de la autonomía personal y atención a las personas en situación de dependencia. Disponible en: http://www.congreso.es/docu/inf_fiscTC/251-46.pdf.

70 Consejo de Política Fiscal y Financiera, Acuerdo 6/2009, de 15 de julio. Disponible en: http://www.minhafp.gob.es/Documentacion/Publico/PortalVarios/FinanciacionTerritorial/Autonomica/AcuerdosConsejo/Acuerdo\%206_2009\%20Reforma\%20Sistema\%20 Financiaci\%C3\%B3n.pdf. 
rios que se utilizaban para el reparto del nivel acordado ${ }^{71}$. La financiación adicional comenzó a tener efectos en los años 2009 y 2010 y se consolidó en 2011.

Estas dos vías de financiación, finalista y adicional, establecidas en sus respectivas leyes, han supuesto que las aportaciones desde los Presupuestos Generales del Estado ascendieran a más de 27.000 millones de euros, desde 2007 hasta $2015^{72}$.

Por otra parte, el Tribunal de Cuentas ha señalado en el citado informe que la financiación adicional de la Ley 22/2009 (LOFCA) compensa con creces la suspensión en 2012 del nivel acordado de financiación.

Sin embargo, el problema de la financiación es que las Comunidades Autónomas solamente consideran, como aportación del Estado, la incluida en los Presupuestos Generales del Estado, correspondiente al nivel mínimo (financiación finalista), y no la incluida en el bloque de la financiación recibida vía LOFCA (financiación no finalista). En otras palabras, como pone de relieve el propio Tribunal de Cuentas, la financiación recibida vía LOFCA en función de los criterios aprobados en 2009, para destinarse a la atención de las personas con algún grado de dependencia, no siempre se emplea en esa materia por parte de las Comunidades Autónomas, es más, no reconocen que se reciba para esa finalidad, y de ahí las reclamaciones por parte de ellas a la Administración General del Estado de una mayor financiación.

La manera de solucionar este problema tiene que venir de la mano de una reforma del modelo de financiación de la Dependencia, y tendría que incorporarse a las negociaciones del nuevo modelo de financiación autonómica. Dicha financiación debe garantizar la sostenibilidad del sistema, y debe garantizarse, en todo caso, que sea finalista, es decir, que las Comunidades Autónomas deban utilizarla exclusivamente para la atención de la Dependencia.

\section{CONCLUSIONES}

Pese a que aún es pronto para hacer una valoración serena y objetiva de las reformas estructurales implementadas, sí es posible afirmar que, en general, se han cumplido los objetivos y fines para los que fueron diseñadas, o al menos algunos de ellos.

En el caso concreto de la reforma de las Administraciones Públicas, los avances en materia de racionalización, supresión de duplicidades, generación de sinergias y optimización de recursos, son palpables en cuanto a volumen, estructuras y costes, con una reducción de más de 166.000 efectivos (un 6,20\%), y una disminución de más de 2.400 entes de los sectores públicos instrumentales administrativos y no administrativos. Cifras que se siguen ampliando, al amparo de la baja reposición de efectivos y los procesos de consolidación empresarial, principalmente en el sector autonómico y local.

En el caso concreto de la reducción de cargas administrativas, los resultados son también muy positivos, no tanto en el aspecto económico como en el que verdaderamente es el más relevante: la mejora de la eficiencia en las relaciones de la Administración con las empresas y ciudadanos.

Sin embargo, y aunque los resultados de la Comisión para la Reforma de las Administraciones Públicas presentan un balance positivo, con unos ahorros estimados de casi 35.000 millones de euros, -11.626 millones de euros en el Estado, 14.276 millones en las Comunidades Autónomas, 5.046 millones en las Entidades Locales y 4.026 millones para ciudadanos y empresas-, lo cierto es que dichas cifras deben ser puestas en tela de juicio, por varios motivos.

En primer lugar, por lo elevado de su cuantía y la metodología empleada para cuantificar dichos ahorros, dado que, aunque resulta lógica la conexión entre la reducción del déficit y la reforma de las Administraciones Públicas, la sustancial reducción del déficit desde 2011 no ha sido resultado exclusivo de dicha reforma,

71 Por tanto, para la Dependencia, el porcentaje de distribución es el $25 \%$ de los fondos adicionales anuales, utilizando criterios de distribución entre las Comunidades Autónomas en función de la población potencialmente dependiente y del número de personas reconocidas como dependientes con derecho a prestación, registradas en el Sistema de Información del Sistema de Atención a la Dependencia, según los datos de la Resolución de 21 de mayo de 2009, del Instituto de Mayores y Servicios Sociales, por la que se publica el Acuerdo del Consejo de Ministros de 8 de mayo de 2009, por el que se aprueba el marco de cooperación interadministrativa y criterios de reparto de créditos de la Administración General del Estado para la financiación durante el 2009 del nivel acordado previsto en la Ley 39/2006, de 14 de diciembre, de promoción de la autonomía personal y atención a las personas en situación de dependencia.

72 Sobre esta cuestión vid., recientemente, Beitia, R. y Pardavila, B., "La Ley de dependencia: costes reales y financiación total durante el periodo 2012-2015", en Revista Española de Discapacidad, 4 (2), 2016, págs. 189-204. DOI: https://doi. org/10.5569/23405104.04.02.10 Asimismo, Prada, M. D. y Borge, L. M. (2015): "Una aproximación al coste de la dependencia en España y su financiación", en Documentación social, 177, 2015, págs. 97-118. 
como parece llegar a entenderse al conectar los ahorros generados por los trabajos de la Comisión con la situación actual del déficit.

En segundo lugar, porque sobreestima el rol desempeñado por el impulso de la Administración Electrónica y la reducción de cargas administrativas que, aunque ha producido éxitos notables e indudables ganancias en eficacia y eficiencia, tiene una trascendencia acompasada a la propia modernización tecnológica de la Administración Pública, por lo que su relevancia no puede ser maximizada, esencialmente en lo relativo a los ahorros generados por las innovaciones técnicas en las relaciones Administración-ciudadanos.

$\mathrm{Y}$, en tercer lugar, porque en el caso concreto del empleo público, tras casi diez años con una tasa de reposición que no alcanza el cien por cien de las bajas sufridas, se empiezan a mostrar algunos efectos adversos de la consolidación de una baja tasa de reposición, especialmente en la proliferación de personal interino aunque, en general, el balance de las medidas de racionalización de empleados públicos puedan considerarse adecuadas, máxime si se tiene en cuenta un factor clave: el empleo público se ha racionalizado fundamentalmente a través de jubilaciones no cubiertas.

En cualquier caso, y como puso de manifiesto la Oficina para la Ejecución de la Reforma de la Administración, OPERA, en su informe trimestral de seguimiento de octubre de 2016, de los ahorros producidos «un $42 \%$ corresponde a remuneración de asalariados y a gastos corrientes», que se han reducido, en ambos casos, un $5 \%$ desde 2011.

Ahorros que evidencian que los capítulos 1 y 2 de gasto, -gastos de personal y gastos corrientes, respectivamente-, han sido los que más han soportado el peso de la racionalización y reforma de las Administraciones Públicas, lo que exige también una reflexión, pro futuro, acerca de las medidas en materia de empleo público.

Algo parecido ocurre en el ámbito de la Educación y la Sanidad. Los efectos más relevantes de las medidas ejecutadas se refieren al ámbito de la contención del empleo público, aunque haya habido ahorros económicos también en otros campos. Sin embargo, como ya hemos puesto de relieve, esta congelación de las plantillas no puede ni debe continuar por mucho tiempo.

En este sentido, sería muy conveniente limitar la extensión y alcance de las medidas de contención en materia de empleo público en el ámbito de la educación y la sanidad y, muy especialmente, la relativa a la tasa de reposición de efectivos que, desde el año 2008, no ha vuelto a alcanzar el 100\% de los efectivos. Casi diez años en los que se ha producido un notable descenso en el volumen de empleados públicos, con importantes ganancias de productividad y competitividad añadidas pero que, también, está conllevando un notable envejecimiento de las plantillas públicas que, de consolidarse, puede afectar a la prestación de los servicios públicos y, más concretamente, a su calidad y eficiencia.

Por último, y en cuanto a las reformas en materia de Dependencia, la excesiva prevalencia de las prestaciones económicas por cuidados en el entorno familiar ha provocado que no se cumplieran las expectativas de generación de empleo inicialmente previstas. Las medidas aprobadas han contribuido al aumento y consolidación en todos los servicios profesionales, en definitiva la apuesta por la profesionalización, lo cual ha tenido una positiva repercusión en la creación de empleo. Pero existen importantes discrepancias entre la Administración Central y la autonómica en lo referido al sistema de financiación, incluso se manejan cifras muy diferentes. Por eso es imprescindible un acuerdo que garantice una financiación sostenible y equilibrada, que sea finalista y permita culminar el pleno desarrollo y eficacia de la Ley, y que solvente esas discrepancias. Este debería ser uno de los elementos claves de la negociación del nuevo sistema de financiación autonómica. 